\title{
Advantages of Vertical Axis Tidal Turbines set in close proximity: a comparative CFD investigation in the English Channel
}

\author{
Stefania Zanforlin*
}

Department of Energy, Systems, Territory and Constructions Engineering, University of Pisa, l.go Lucio Lazzarino, 56122 Pisa, Italy.

* Corresponding author. Tel.: +39-050-2217145; fax: +39-050-2217150; e-mail address:

s.zanforlin@ing.unipi.it.

\begin{abstract}
A CFD analysis of the hydrodynamic interactions between three closely spaced Vertical Axis Tidal Turbines is performed for two layouts: side-by-side and triangular. Three mechanisms determine a power increase with respect to isolated turbines: (1) turbine blockage that entails flow acceleration outside of the turbines and inside the aisles between adjacent turbines; (2) more favorable direction of the flow approaching the blade during upwind trajectory; (3) wake contraction, that increases the torque generation during the downwind path. Blockage is responsible for a moderate performance increase exhibited by the triangular layout. Change in direction of the flow approaching the blades and wake contraction only occur for the side-by-side layout and cause a significant increase in efficiency. The six-month energy production of the two arrangements is predicted for three real cases in the English Channel: Alderney Race, St. Catherine and Portland Bill, characterized by rectilinear and non-rectilinear currents. Passive stall is assumed as load strategy control; the effect of the rated speed on energy production is analyzed. The side-by-side layout allows not only a higher power gain but also a wider range of flow directions for which a gain is possible, therefore it appears suitable even for non-rectilinear currents.
\end{abstract}

Keywords: vertical axis tidal turbine; wake; blockage; hydrodynamic interactions; farm.

\section{Nomenclature}

\begin{tabular}{|c|c|c|}
\hline \multicolumn{2}{|c|}{ Latin symbols } & $\mathrm{U}_{\infty} \quad$ free stream velocity magnitude $[\mathrm{m} / \mathrm{s}]$ \\
\hline AR & turbine aspect ratio & $\mathrm{U}_{\mathrm{x}} \quad$ absolute $\mathrm{x}$-velocity at blade position $[\mathrm{m} / \mathrm{s}]$ \\
\hline \multirow[t]{2}{*}{ B } & number of blades [-] & absolute $y$-velocity at blade position $[\mathrm{m} / \mathrm{s}]$ \\
\hline & & dimensionless wall distance [-] \\
\hline $\mathrm{c}$ & blade chord $[\mathrm{m}]$ & \\
\hline $\mathrm{D}$ & turbine diameter $[\mathrm{m}]$ & Greek symbols \\
\hline $\mathrm{C}_{\mathrm{P}}$ & power coefficient [-] & $\alpha \quad$ blade relative angle of attack $[\mathrm{deg}]$ \\
\hline $\mathrm{H}$ & blade length $[\mathrm{m}]$ & layout orientation respect to North [deg] \\
\hline $\mathrm{k}_{\mathrm{i}}$ & normalized power coefficient of the turbine in the arrangement & blade azimuthal angle $[\mathrm{deg}]$ \\
\hline $\mathrm{K}$ & normalized power coefficient of the overall arrangement $[-]$ & air kinematic viscosity $\left[\mathrm{m}^{2} / \mathrm{s}\right]$ \\
\hline $\mathrm{N}$ & number of turbines belonging to the arrangement & air density $\left[\mathrm{kg} / \mathrm{m}^{3}\right]$ \\
\hline $\mathrm{P}$ & power of the isolated turbine $[\mathrm{W}]$ & Blade solidity [-] \\
\hline$P_{i}$ & power of the turbine in the arrangement $[\mathrm{W}]$ & current direction respect to the arrangement [deg] \\
\hline $\mathrm{R}$ & turbine radius $[\mathrm{m}]$ & turbine angular velocity $[\mathrm{rad} / \mathrm{s}]$ \\
\hline $\operatorname{Re}_{\mathrm{c}}$ & chord-based Reynolds number [-] & \\
\hline TSR & tip-speed ratio $[-]$ & \\
\hline
\end{tabular}




\section{Introduction}

Tidal currents energy has been identified as one of the most promising renewable resources in Europe. It has important advantages with respect to wind or wave power, such as predictability and invisibility, and offers important attractions to power distribution and supply companies.

Horizontal or vertical axis turbines can be used. The main advantages of vertical axis tidal turbines (VATT) are their cost-effectiveness, construction simplicity and finally they are omnidirectional thus there is no need for any yaw device. Further advantages could be achieved if floating platforms were employed, as the generator and the gearbox could be placed in an easily accessible position above the sea level, and it would be possible to harvest a significantly higher current compared to devices close to the sea bottom. In addition the motion of the overall structure would affect the energy output negligibly, as vertical axis turbines show good performances even in skewed flows [1]. On the other hand, VATTs are penalized by self-starting issues and by lower efficiency compared to horizontal axis tidal turbines (HATT), even though both these problems could in theory be mitigated by using blade-pitching systems [2-4] at the cost of a more complicated overall system. The development of VATTs for tidal harvesting has just begun, however the progress that is expected in a near future in the field of offshore floating vertical axis wind turbines (VAWTs) could address solutions to mitigate those technological problems that are intrinsic to the vertical axis concept.

In order to compensate the relatively low efficiency of the individual rotor, it is essential increase the power density as well as the efficiency of the overall farm or small arrangement. To increase the power produced in a given area of sea it would be convenient to adopt high aspect-ratio turbines (for instance an AR $\sim 2$ or more) by making use of the possibility to set the turbine height independently from their diameter. To enhance the farm overall efficiency the turbines must be arranged closely enough to take advantage of blockage effects while, at the same time, paying attention to avoid the negative effects of wake interactions. Numerical studies aimed to optimize the arrangement of HATT arrays prove that local blockage mechanisms (acceleration of the flow between two adjacent turbines) can be exploited to increase both the packing factor and the overall efficiency by dislocating the turbines belonging to two consecutive rows in staggered arrangements [5-9]. Moreover, vertical axis turbines set in close proximity exhibit peculiar characteristics that have been investigated for the first time by Dabiri and his team [10-13], who measured a performance increase by placing turbines not only in staggered rows but also in 2-counter-rotating-turbines arrays, placed in very close proximity. Their experiments show a wind speed recovery to $95 \%$ of the far field wind speed within just 6D [12]. The theoretical models they implemented are focused on the evolution of the energy content of the field and on the energy recovery in the wakes, which is much faster than that typical of HAWT rows, making possible higher packing factors. However, the turbines are modelled as bluff bodies in which a negative source of momentum is superimposed to take into account the power extracted [13]. This assumption makes the model only partially able to explain the reasons for the enhanced performance of a turbine belonging to a pair with respect to an isolated turbine subjected to the same blockage effect generated by the upstream row.

The interference between two VATTs, both counter-rotating or co-rotating, has been investigated experimentally and numerically by Li and Çalişal [14], yet their model, based on the vortex approach, does not allow in-depth understanding of the physical phenomena that determine a power increase or a detriment depending on the relative arrangement (angular position and distance) of the rotors. A vortex approach has also been adopted by Feng et al. [15] to predict the behavior of two counter-rotating closely spaced VAWTs versus wind direction. 
Despite a large number of Unsteady Reynolds Averaged Navier-Stokes (URANS) CFD investigations of single vertical axis, both wind or tidal, turbines, there are still few analyses on wake interferences in two or more turbine arrangements. A first attempt to investigate the interactions between arrangements of closely spaced vertical axis wind turbines by means of CFD was done by Giorgetti et al. [16] who focused on the wake reenergisation due to wake contraction. Recently, Zanforlin and Nishino [17] performed a comprehensive set of 2D URANS simulations of the flow around a pair of counter-rotating vertical-axis wind turbines with various gaps between the rotors, tip-speed-ratios and wind directions. They observed that the mechanisms playing an important role in performance increase with respect to an isolated turbine are the improvement in the direction of the flow approaching the blade in the upwind path and the increase of the velocity magnitude in the downwind trajectory due to wake contraction. Starting from these findings and from a preliminary investigation that has shown mutually beneficial effects also in a small VATT arrangement [18], the hydrodynamic interactions between three closely spaced VATTs arranged in two layouts, side-by-side and triangular, are compared in the present study as a function of the relative distance between axes and of the current direction. Afterwards, the energy production of the two arrangements over a period of six months is predicted for three real cases in the English Channel characterized by different speed and degree of bidirectionality of currents, focusing on the effects of the load control strategy.

\section{Model set-up and validation}

In this section the set-up of the CFD model is specified. The validation tasks concerning the sensitivity of the results to the domain dimensions and to the revolution number is carried out for the turbine simulated in section $3(\mathrm{D}=1.0 \mathrm{~m})$, whereas the validation of the overall model is done for a small water turbine (same geometry, scaled, $\mathrm{D}=0.175 \mathrm{~m}$ ) for which experimental data are available in literature.

\subsection{Turbulence model and discretization schemes}

Turbulence is modeled by means of the k- $\omega$ SST (Shear Stress Transport) model that is widely used in the simulation of VAWTs [19-23]. The k- $₫$ model of Menter [24, 25] is well suitable for flows with strong adverse pressure gradient and flow reversal as those involved by VAWT especially when operating at low Tip Speed Ratio (TSR), defined as:

$$
T S R=\frac{\Omega R}{U_{\infty}}
$$

The SST formulation is a variant of the standard k- $₫$ model, combining the original Wilcox k- $₫$ model [26] for use near walls and the standard k- $\varepsilon$ model away from walls using a blending function, and the eddy viscosity formulation to account for the transport of the principle turbulent shear stress. The SST formulation switches to a $k-\varepsilon$ behavior in the free-stream avoiding the problem of the too much k-@ sensitivity to the inlet freestream turbulence properties [19]. The grids of the current study are unstructured with the adding of regular quad element layers all around the blade wall to predict the boundary layer. The wall distance from the first layer of cells must be set to keep y+ low enough to capture flow separation phenomena. Maître et al. [19] evaluated the influence of $\mathrm{y}+$ on results finding that averaged $\mathrm{y}+>1$ leads to an overestimation of pressure drag in turbines subjected to significant flow separation as typically occurs for high solidity water turbines. Another experimental and numerical investigation on a high solidity small VAWT in a tow tank has been done by Bachant and Wosnik [27] who analyzed the near wake characteristics by means of CFD 2D and 3D adopting 
$\mathrm{k}-\oplus$ SST with $\mathrm{y}+\sim 1$. According to literature, for the validation of the overall model (section 2.4) the maximum $\mathrm{y}+$ is 0.42 and the mean is 0.16 , whereas for the other validation tasks (sections 2.2 and 2.3) and for the simulations of chapter 3 the maximum $y+$ is 1.05 and the mean is 0.39 .

The CFD software used for the simulations is ANSYS Fluent v15 with PISO (Pressure-Implicit with Splitting of Operators) velocity-pressure coupling algorithm. The spatial discretization is set to least squares cell based for gradient, and PRESTO! (PREssure STaggering Option) for pressure. Second order schemes are used for pressure, momentum, turbulent kinetic energy $(\mathrm{k})$ and specific dissipation rate $(\omega)$ formulations. A second order implicit method is also set for the temporal discretization.

Absolute convergence criteria are set to $1 * 10^{-4}$ for the residuals of each variable (continuity, velocity components, turbulence kinetic energy and specific dissipation rate).

To simulate the turbine rotation two different grid levels are used: a fixed sub-grid with the external dimensions of the flow domain and a rotating sub-grid for each turbine in relative motion with respect to the fixed grid by means of the sliding mesh technique. When using a sliding mesh, it is known [28] that to have a good numeric convergence characteristic, the value of the time step should not be larger than the time it takes for a moving cell to advance of the cell characteristic size. To save computation time, we adopt a coarse time step corresponding to $1^{\circ}$ revolution for the first 10 revolutions; hereafter, since there are 720 cells on the sliding interface, a time-step corresponding to $0.5^{\circ}$ is set for the last 8 revolutions. This choice agrees with the observations of Balduzzi et al. [29]. They note that, in most of the CFD simulations of VAWTs, it corresponds to the lapse of time in which the rotor makes a rotation between $0.5^{\circ}$ and $2^{\circ}$. Moreover, they performed a sensitivity analysis using angular time-steps between $0.135^{\circ}$ and $0.405^{\circ}$ finding relevant differences only for very low TSRs. The setting of this study also agrees with the time dependence study of Elkhoury et al. [30] who found extremely close results by setting time-steps of $1.2^{\circ}$ and $0.6^{\circ}$, and satisfies the indications by Marsh et al. [20] who found result independence for a time-step of $0.9^{\circ}$.

\subsection{Domain size dependency}

A rectangular computational domain is adopted. Most of the grid elements are located in the rotating domains (135000 cells for each turbine), around the turbines and in the near-wake. The total cell number depends on the rectangle's dimensions. Since the aim of the study is to evaluate the influence of the blockage coming from mutual interferences between turbines, it is essential to avoid that lateral boundary blockage or inlet domain length lead to an overestimation of $\mathrm{C}_{\mathrm{P}}$ due to an increase in velocity magnitude of the oncoming flow. Therefore the dimensions of the external fixed domain must be set much larger than the minimum ones recommended in literature [31]. For this purpose, a sensitivity analysis is done to check the influence of the domain width (i.e., in crosswise direction with respect to the water direction) and of the upstream length (i.e., from the inlet boundary to the turbines). Simulations are done for the isolated turbine and for side-by-side layout with distance between axes of 1.5D and 3.5D. TSR is set to 1.75 as best compromise, as will be explained in section 3.2. Before analyzing the results, some performance parameters need to be specified. The power coefficient of the isolated turbine $\left(\mathrm{C}_{\mathrm{P}}\right)$ is:

$$
C_{P}=\frac{P}{\frac{1}{2} \rho(H D) U_{\infty}^{3}}
$$

For the turbine belonging to a multi-device arrangement a normalized power coefficient $\left(\mathrm{k}_{\mathrm{i}}\right)$ is defined with respect to the performance of the isolated turbine: 


$$
k_{i}=\frac{P_{i}}{P}
$$

For the overall arrangement, composed of $\mathrm{N}$ turbines, an averaged normalized power coefficient $(\mathrm{K})$ is calculated as:

$$
K=\frac{\left(\sum_{i=1}^{N} P_{i}\right) / N}{P}
$$

Fig. 1-a shows $C_{P}$ (or, in case of the arrangement, the averaged $C_{P}$ ) normalized with respect to $C_{P}$ calculated for a domain width of 150D that can be considered "infinite". Two observations are worthy of note: as expected [29], the larger is the domain the lower is the performance; multi-device arrangements need a larger domain to achieve the same degree of result independence of an isolated turbine. For instance, a width of 48D may not appear sufficient in case of three VATTs. However since we are more interested in a comparative analysis (arrangement performance vs isolated turbine performance) rather than an absolute analysis, the most significant parameter to check is K. As shown in Fig. 1-b, a width of $48 \mathrm{D}$ leads to a difference in $\mathrm{K}$ values, respect to $\mathrm{K}$ calculated for a domain width of $150 \mathrm{D}$, of $3.5 \%$ and $3.8 \%$, for a distance between axes of $1.5 \mathrm{D}$ and 3.5D respectively. These divergences correspond to overestimate the performance gain on the isolated turbine of just $10.9 \%$ and $17.1 \%$, respectively. About the effect of the upstream length, the result independence is achieved with a length of 36D, as documented in Fig. 1-c and 1-d.

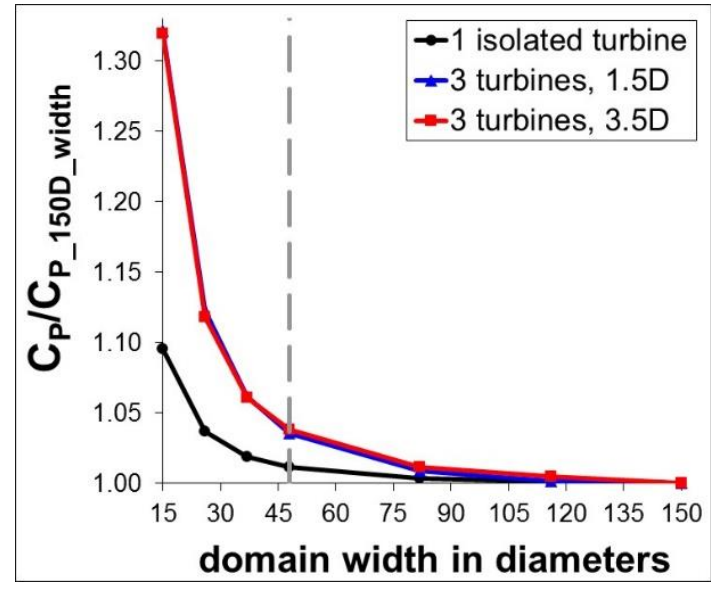

(a)

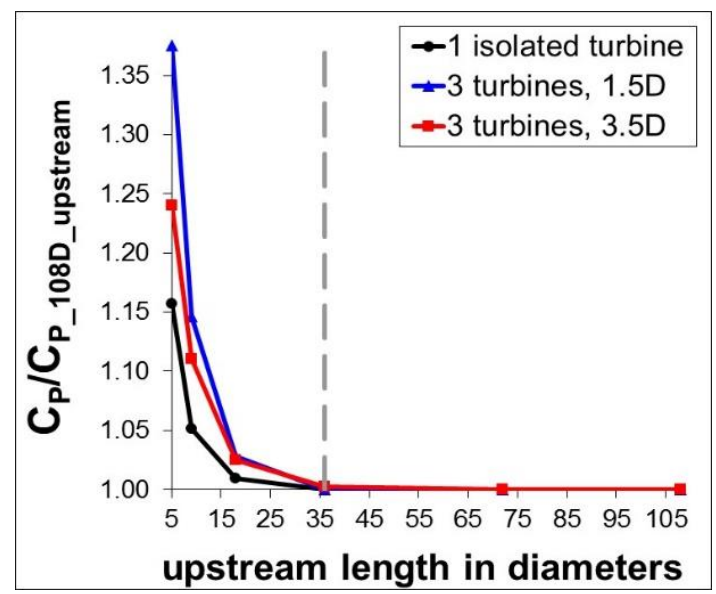

(c)

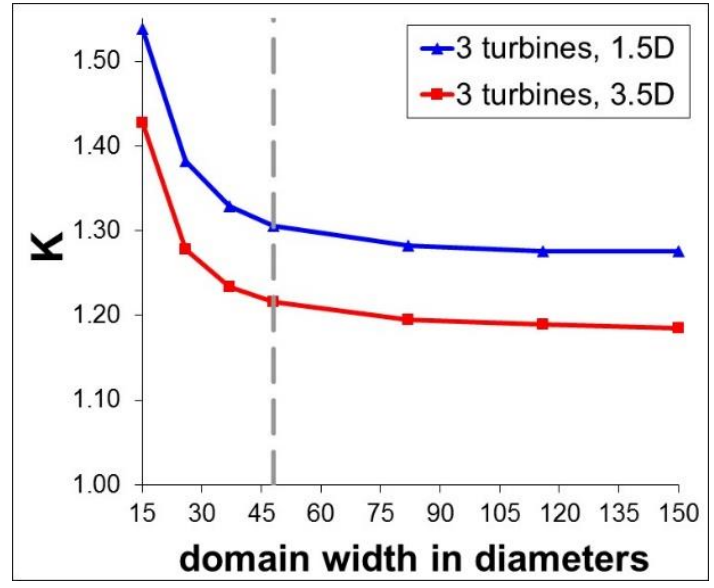

(b)

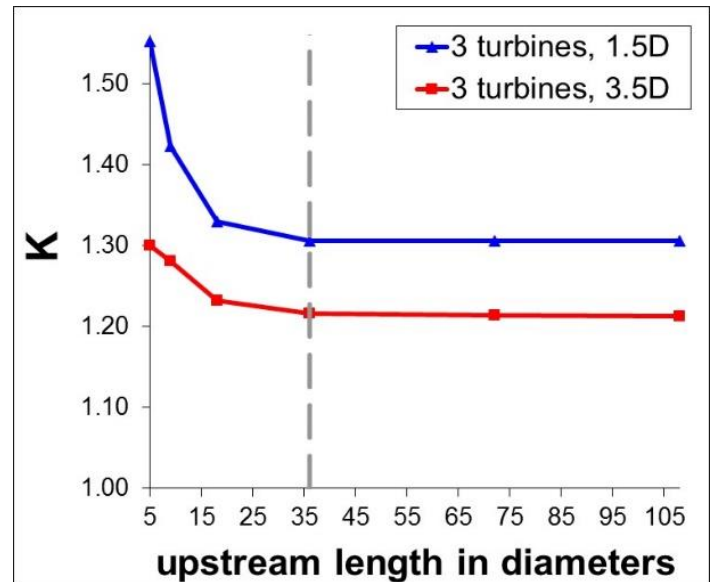

(d)

Figure 1. (a) performance normalized with respect to the performance calculated for a domain width of 150D, vs domain width; (b) K vs domain width; (c) performance normalized with respect to the performance calculated for an upstream length of 108D, vs domain upstream length; (d) K vs domain upstream length. For the side-by-side arrangement the turbines are spaced 1.5D and 3.5D. 
It must be pointed out a substantial difference in setting width and upstream length. In some cases domain width need to be "finite" because of a physical confinement (for instance, to simulate a channel) or even wanted to take advantage from some kind of confinement (for instance, the presence of other arrangements). On the other hand, upstream length must be "infinite" since a length that is too short is a physically unjustifiable mistake. In agreement with the above results, domain crosswise width and inlet length are set to 48D and 36D respectively, while the downstream length is $20 \mathrm{D}$, according to the literature [31]. With these dimensions the total cell number results 260000 in case of single turbine, and 630000 for side-by-side and triangular 3-VATT layouts.

\subsection{Solution convergence}

One hundred revolutions have been simulated for the isolated turbine and for the side-by-side layout with a distance between the axes of $1.5 \mathrm{D}$, to find out the minimum number of revolutions to obtain a converged solution. In addition three different flow directions ( $\varphi$, as defined in the pane overlapped to Fig. 2-a) have been considered: $0^{\circ}, 30^{\circ}$ and $45^{\circ}$. The results of Fig. 2 suggest that the solution can be deemed satisfactorily converged after 50 revolutions. Unfortunately, such a number of revolutions would require prohibitive computational times considering that the current research implies more than 300 simulations, therefore a lower number was chosen. Fig. 2-a indicates that after 18 revolutions the isolated turbine and the arrangement exhibit a performance overestimation ranging between $3.2 \%$ and $6.5 \%$ with respect to the performance calculated after 100 revolutions. Nonetheless, after 18 revolutions K trends in Fig. 2-b are already well defined. In fact, the K overestimation is almost negligible for $\varphi=30^{\circ}$ (just $0.6 \%$ ) while is significant for $\varphi=45^{\circ}(+1.7 \%$, that corresponds to overestimate of about $50 \%$ the performance enhancing on the isolated turbine). Yet for $\varphi=0^{\circ}$, that is the most significant condition in this study, $\mathrm{K}$ is still rising and the discrepancy between 18 and 100 revolutions corresponds to underestimate of $6.6 \%$ the performance enhancing.

For this reason, 18 revolutions have been set in case of isolated turbine and side-by-side layout. However, 23 have been set in case of triangular layout to take into account that, due to the greater distance between the turbine axes, more time is required for the development of wakes.

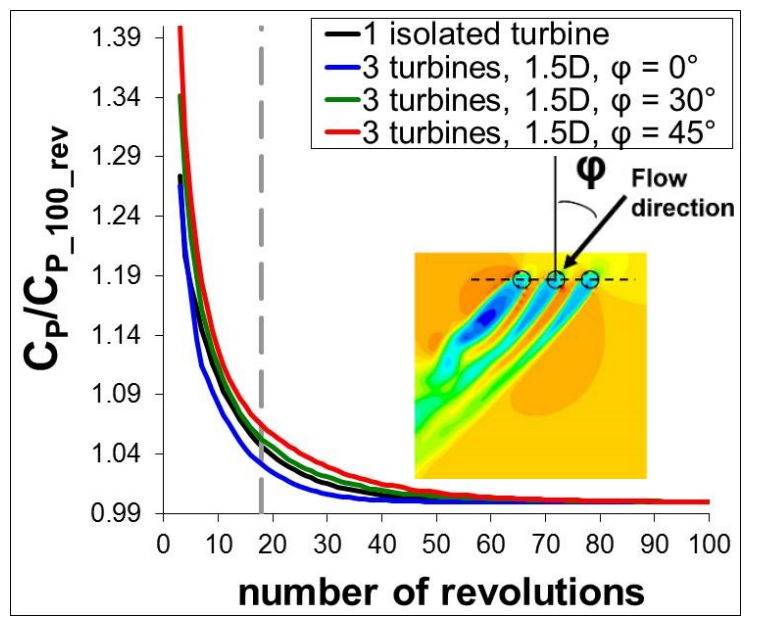

(a)

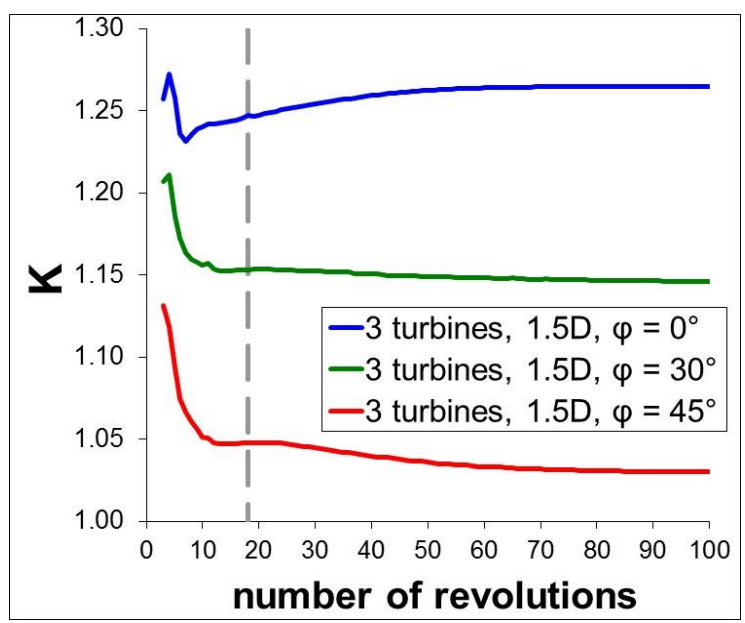

(b)

Figure 2. (a) performance normalized with respect to the performance calculated at 100 revolutions, vs revolution number; (b) K vs revolution number. For the side-by-side arrangement three flow directions $\varphi$ (defined in the pane) are simulated: $0^{\circ}, 30^{\circ}, 45^{\circ}$.

\subsection{Overall validation of the model for a small water turbine}


The validation of the overall computational model is performed for a small 3-bladed H-Darrieus water turbine tested by Maître et al. [19] in a hydrodynamic tunnel. Turbine diameter (D) and blade length (H) are 175mm, therefore the aspect ratio AR (AR=H/D) is 1 . The hydrofoil shape is a modified version of a NACA0018 obtained warping the profile from the mid-chord such that the camber line fits the circular blade path (Fig. 3a). The chord (c) of the modified cambered section is $32 \mathrm{~mm}$ length. Therefore the solidity $(\sigma)$, defined as:

$$
\sigma=\frac{B c}{2 \pi R}
$$

is 0.175 . This data has been chosen since these blade profile and solidity are quite common in tidal turbine studies, moreover other data is available for a wide range of $\sigma$ in tunnel [32] and for a full scale turbine with the same $\sigma$ in open sea [33]. The free stream speed $\left(\mathrm{U}_{\infty}\right)$ is $2.8 \mathrm{~m} / \mathrm{s}$ and the chord-based Reynolds number $\left(\operatorname{Re}_{c}\right)$, defined as:

$$
R e_{c}=\frac{c R \Omega}{v}
$$

is 179000 at the optimum TSR of 2. To simulate the turbine operating in conditions as similar as possible to those inside the water tunnel, the same width of the test-section is adopted for the computational domain in order to take into account the horizontal solid blockage. Yet, a longer domain is chosen upstream to allow the developing of a realistic non-uniform velocity profile before the rotor, since the only data known is the mean flow speed based on the flow rate elaborated by the pump. The domain length downstream is set to accomplish the full development of the wake in order to avoid numerical problems on the outlet boundary. Thus, as done by Ferreira for wind tunnel tests [34], inlet and outlet are placed 10D upwind and 14D downwind with respect to the rotor axis. Fig. 3-b shows a comparison between numerically predicted and experimental $\mathrm{C}_{\mathrm{P}}$ versus TSR. The high values of experimental and numerical $C_{P}$ can be justified by the high blockage ratio (frontal turbine area / test-section area $=0.35)$ that increases the speed of the flow approaching the turbine. It can be noticed that CFD-2D results significantly overestimate the experimental results, however the trend of the $\mathrm{C}_{\mathrm{P}}-\mathrm{TSR}$ curve and the optimal TSR are matched. Since the blade-based aspect ratio (H/c) is quite low (just 5.5) it is expected that tip losses substantially penalize the performance. To take into account of tip losses and other important 3D effects such as the vertical blockage of the water tunnel, in the current study additional CFD-3D simulations have been performed with a high-quality structured multi-block grid, achieving numerical results fairly close to the experimental ones (Fig. 3-b). This proves that the discrepancy between CFD-2D and experiments are due to 3D effects and not to poor consistency of the numerical model.

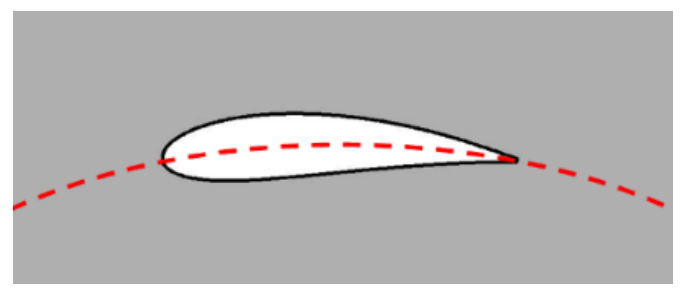

(a)

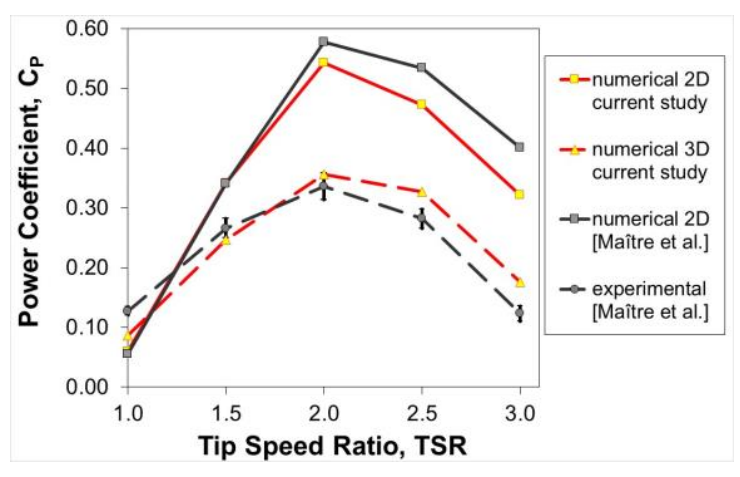

(b)

Figure 3. (a) Blade path (red dashed line) and blade profile of the warped NACA0018; (b) comparison between experimental performance [19] and CFD predictions obtained for the small turbine in water tunnel. 


\section{Results}

After a qualitative description of the physical mechanisms that determine a power increasing with respect to isolated turbines, the performance enhancing achieved by closely spaced side-by-side and triangular layouts is justified by means of the angle of attack and flow velocity distribution at the blade position. Then the effects of the current direction and distance between turbines are analyzed at the optimum TSR. Afterwards the focus is moved on the effects of the load control strategy on the behavior of the VATTs for the two layouts, in comparison to the behavior of the isolated turbine. Finally, the energy output gains predicted in a six months period for the layouts set in three locations of the English Channel are shown and discussed. The turbine simulated in all the sections is geometrically similar to that adopted for the overall validation of the model (section 2.4), therefore solidity and blade profile are the same, yet the scale is different since the diameter is $1.0 \mathrm{~m}$ and consequently, chord is $183 \mathrm{~mm}$.

\subsection{Mutual interaction phenomenology}

In this section the behavior of three VATTs set in close proximity is analyzed by means of 2D-CFD simulations, with the aim of identifying the main interaction mechanisms that affect the turbine performance. The water speed is $1.5 \mathrm{~m} / \mathrm{s}$, a representative value for tidal currents exploitable for power production. The TSR is 1.75 (this choice will be justified in next section). A schematic representation of the upwind and downwind paths of the blade in one revolution is given in Fig. 4. The blade angular position is defined by $\theta$. Regardless of the rotation sense (anticlockwise or clockwise) the upwind path $(0 \leq \theta \leq 180)$ begins with the blade chord aligned to the current, the downwind path covers the range $180 \leq \theta \leq 360$.

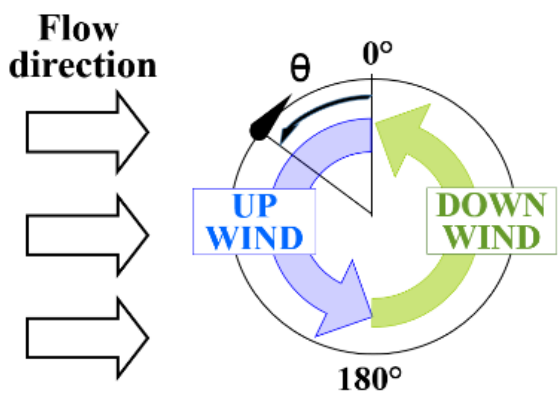

Figure 4. Schematic representation of the upwind and downwind paths of the blade during one revolution.

In the first layout we are going to analyze the VATTs are arranged side-by-side (i.e., the line connecting the axes is perpendicular to the direction of tidal stream) with a distance between axes of 1.5D. Turbines are twoby-two counter rotating: according to the rotation verse highlighted in Fig. 5-b, the wakes of the lower pair of turbines should slightly diverge laterally (in y-direction) whereas the wakes of the upper pair should slightly converge. In fact, as can be seen in much greater extent for a flow past a rotating cylinder, the flow field downstream of a VATT is asymmetric with a tendency to turn in the direction of rotation. However the turbine is permeable to the oncoming flow and thus the wake is bent of just a few degrees. It is interesting to observe that the two pairs exhibit slightly different performance: the turbine at the top gives $\mathrm{k}_{\mathrm{i}}=1.250$, while the turbine at the bottom gives $\mathrm{k}_{\mathrm{i}}=1.226$. An opposite trend is found in pairs of turbines characterized by a lower solidity [16], such as wind turbines, although the physical reasons are still not clear. The normalized power coefficient (K) of the overall arrangement is 1.246. This significant power gain achieved with respect to the isolated 
turbine can be qualitatively explained analyzing the streamlines depicted in Fig. 5-a, 5-b and 5-c. Three phenomena are noticeable:

- turbine blockage that entails flow acceleration on the sides of each turbine and, for the 3-VATT arrangement, inside the narrow aisles between turbines (high velocity red-zones in Fig. 5-a and 5-b);

- $x$-alignment of the flow approaching the turbines at the inner sides of the layout (inner sides of both the counter-rotating pairs, Fig. 5-b), while in case of isolated turbine the flow diverges at the sides;

- contraction of the near-wake at the inner sides of the layout (particularly noticeable for the wake of the central turbine, Fig. 5-b). This implies higher velocity of the flow during the blade downwind phase, as noticeable comparing the velocity colors in the near-wake region for isolated turbine and for the turbines belonging the arrangement.

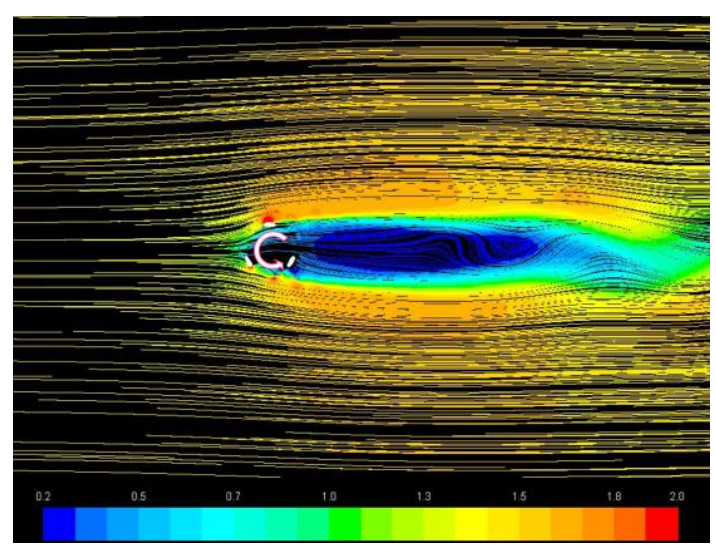

(a)

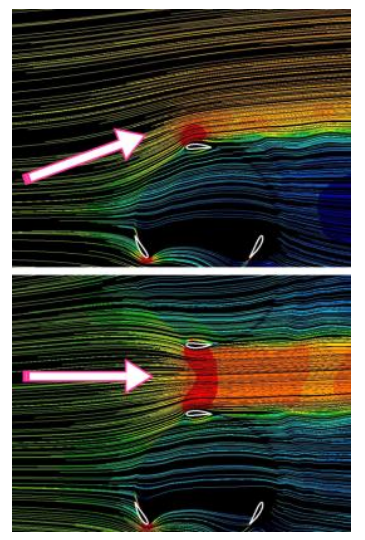

(c)

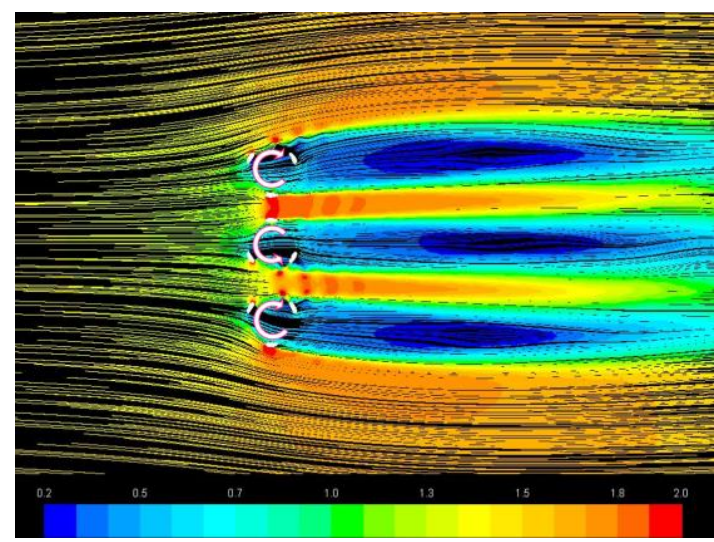

(b)

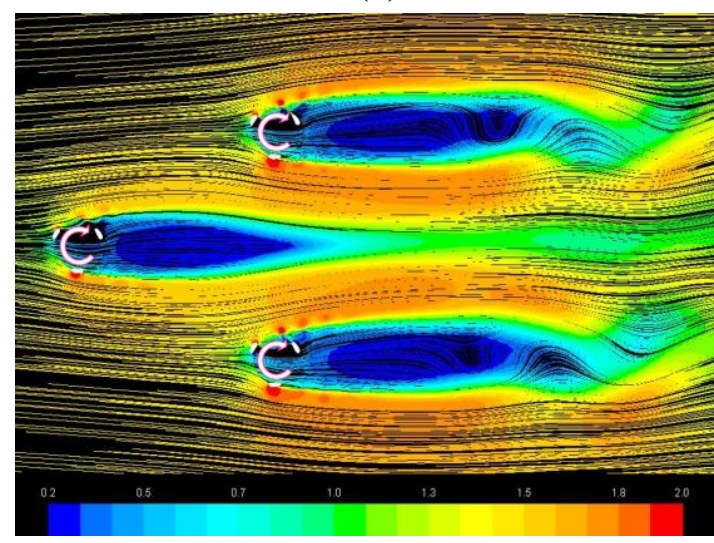

(d)

Figure 5. Streamlines colored with field velocity magnitude [range of the color map $0.2 \div 2 \mathrm{~m} / \mathrm{s}$ ]: (a) isolated turbine; (b) side-by-side layout; (c) details of direction of the flow approaching blades for isolated turbine (top) and for the central turbine of side-by-side layout (bottom); (d) triangular layout. Rotation verse is indicated by a circular arrow. Blade profiles are highligted in white.

Fig. 5-c gives details of the streamlines around the isolated turbine (top-figure) and the central turbine of the arrangement (bottom-figure). It can be seen that the direction of the flow approaching the blade belonging to the arrangement is more longitudinal, which results in a higher flow incidence on the blade and as a consequence, in greater torque. The x-alignment of the flow approaching the blade occurs at all the inner sides of the configuration: at the beginning of the upwind side for the upper turbine, at the end of upwind side for the lower turbine, throughout the whole upwind side for the central turbine of the layout, that exhibits the best $k_{i}$ (1.262). This mechanism justifies the behavior of the single-blade instantaneous $C_{P}$ registered for the three turbines of the layout, shown in Fig. 6-a. In comparison to the isolated turbine, the torque production starts early for the upper turbine, lasts longer for the lower, and both the events happen for the central one. 
One-blade $\mathrm{C}_{\mathrm{p}}$ : isolated turbine vs side-by-side layout

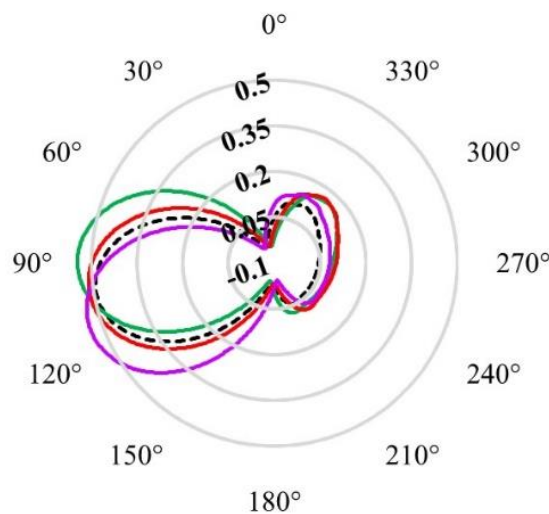

(a)

Flow/blade attack angle: isolated turbine vs side-by-side layout

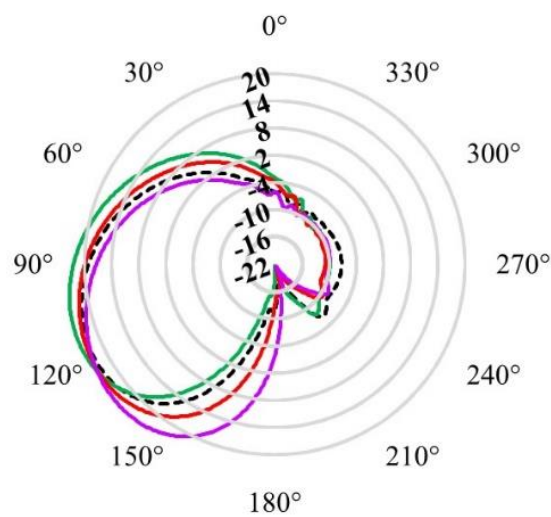

(c)

Local adimensional velocity $\left(\mathrm{U}_{\mathrm{x}} / \mathrm{U}_{\infty}\right)$ : isolated turbine vs side-by-side layout
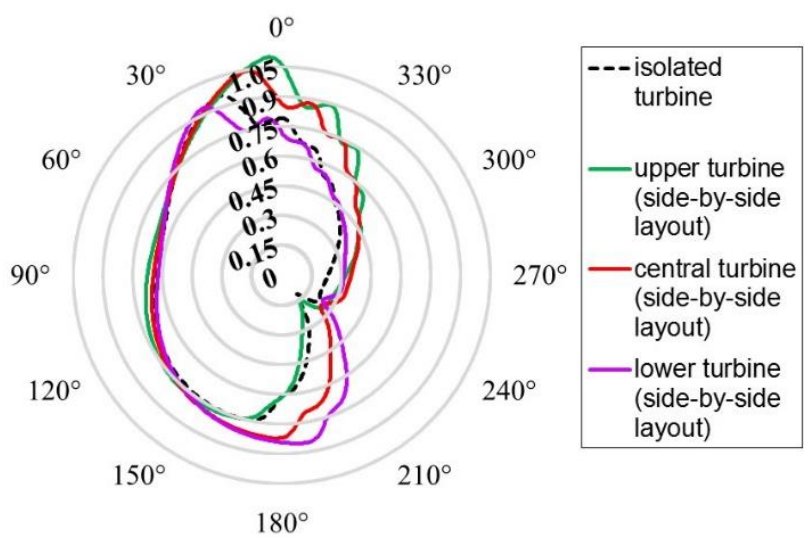

(e)

\section{One-blade $\mathrm{C}_{\mathrm{p}}$ : isolated turbine vs triangular} layout

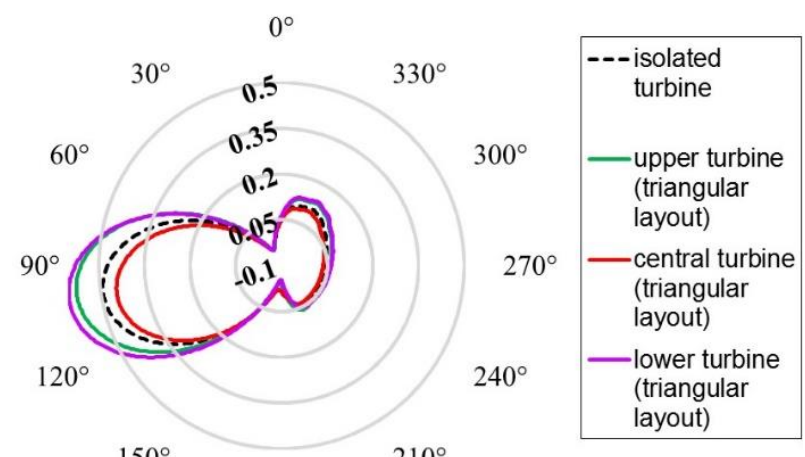

$180^{\circ}$

(b)

Flow/blade attack angle: isolated turbine vs triangular layout

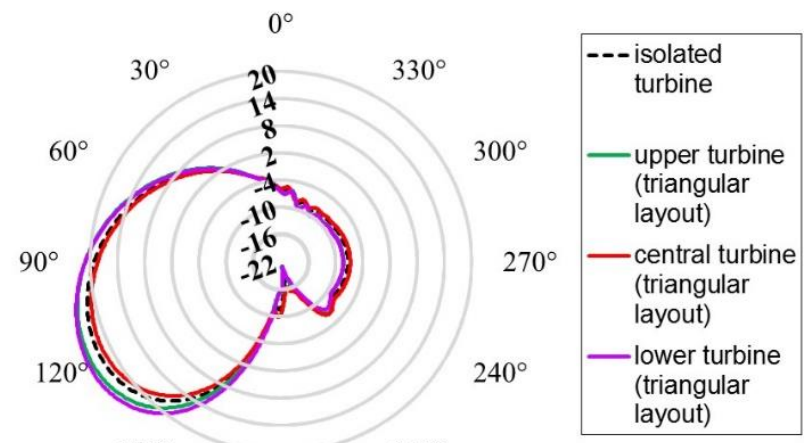

$150^{\circ}$

$210^{\circ}$

$180^{\circ}$

(d)

Local adimensional velocity $\left(\mathrm{U}_{\mathrm{x}} / \mathrm{U}_{\infty}\right)$ : isolated turbine vs triangular layout

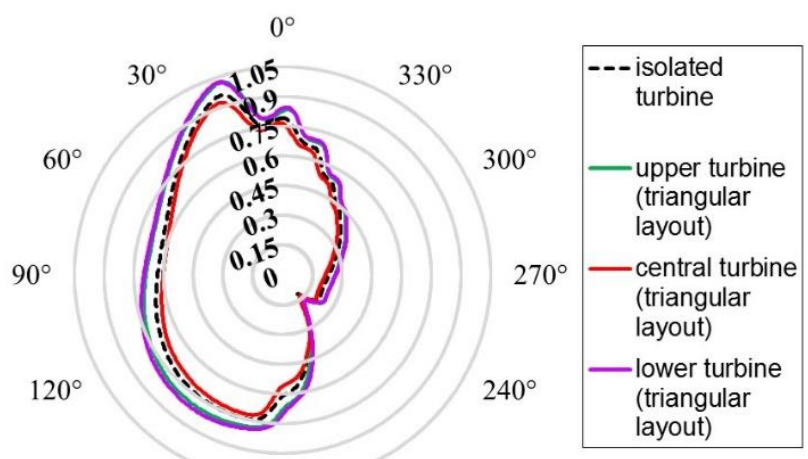

$150^{\circ}$

$210^{\circ}$

$180^{\circ}$

(f)

Figure 6. Instantaneous one-blade $C_{P}$ for the isolated turbine and the VATTs of to side-by-side (a) and triangular (b) layouts; attack angle of the flow approaching the blade for the isolated turbine and the VATTs of to side-by-side (c) and triangular (d) layouts; flow x-velocity (divided by $U_{\infty}$ ) at the blade position for the isolated turbine and the VATTs of side-by-side (e) and triangular (f) layouts.

The $C_{P}(\vartheta)$ polar graph also reveals a significant power increase in the downwind side for the turbines of the side-by-side arrangement, which can be imputed to the aforementioned higher flow velocity inherent to the 
wake contraction induced by the close proximity of the turbines. This phenomenon is particularly strong for the central turbine, since the wake is constrained on both its sides.

It is worth noticing that the key mechanisms for the performance enhancement in both upwind ( $\mathrm{x}$-alignment of the incoming flow) and downwind (wake contraction) sides are the same observed for pairs of vertical axis wind turbines (Zanforlin and Nishino, [16]). Moreover, similar mechanisms were found to be the reason byond the power enhancement of a ducted VAWT (Zanforlin and Letizia, [36]).

Afterwards we analyzed the behavior of three VATTs set at the vertices of an equilateral triangle with a distance between axes of 4.6D. Streamlines and flow velocity magnitude are depicted in Fig. 5-d. For the triangular layout an overall gain is found $(\mathrm{K}=1.105)$, yet the downstream turbines improves its performance $\left(\mathrm{k}_{\mathrm{i}}=1.073\right.$ for the upper turbine, and $\mathrm{k}_{\mathrm{i}}=1.219$ for the lower turbine) while the upstream registers a loss $\left(\mathrm{k}_{\mathrm{i}}=0.884\right)$. Gain and loss can be explained as blockage effects. Indeed, the blockage generated by the upstream turbine deviates the flow laterally, towards the downstream turbines that elaborates a higher flow rate, producing more torque, as shown in the one-blade $C_{\mathrm{P}}(\vartheta)$ polar graph in Fig. 6-b. On the other hand, the blockage from the downstream turbines prevents the complete development of the wake of the upstream turbine, reducing the flow rate elaborated by it, and therefore its power. By comparing the $C_{P}(\vartheta)$ polar graphs of Fig. 6-a and 6-b, neither x-alignment effects (extension of the angular range producing torque in upwind) nor wake contraction effects (significant torque increasing in downwind) are found for the triangular arrangement. Two conclusions can be deduced. First, effective x-alignment and wake contraction only occur in side-by-side arrangements, as observed also for staggered pairs of vertical axis wind turbines [16]. Secondly, the only power increase achievable in triangular layouts (as well as in turbine staggered rows) comes from the blockage occurring at the sides of the upstream turbine(s).

As shown by Raciti Castelli et al. [35] an effective way to evaluate the energy performance of a straight-bladed Darrieus turbine is to graphically represent the evolution of both the rotor torque (or $\mathrm{C}_{\mathrm{P}}(\vartheta)$ ) and blade angle of attack, $\alpha(\vartheta)$, which plays an essential role in determining the performance of vertical axis turbines. The angle of attack as a function of the blade azimuthal position is calculated from the components of the absolute flow velocity at the blade position, $U_{x}(\vartheta)$ and $U_{y}(\vartheta)$, that are registered along the trajectory of the blade during the CFD simulation. The critical issue of this approach is how and where to measure the velocity components in relation to the instantaneous position of the blade. In the current study the rigorous procedure proposed in [35] is greatly simplified by registering $\mathrm{U}_{\mathrm{x}}(\vartheta)$ and $\mathrm{U}_{\mathrm{y}}(\vartheta)$ in a point moving simultaneously with the blade, and located at a certain distance ahead. The optimal distance results from a compromise, as the absolute flow velocity is perturbed by both the bound circulation around the blade and by its wake. By means of a preliminary CFD investigation it has been verified that a satisfactory compromise is achievable by setting the detecting point in the range $1.20 \mathrm{c} \div 1.75 \mathrm{c}$, therefore the point was set at $1.5 \mathrm{c}$. This choice is arbitrary and even though it affects the absolute results, it does not significantly influence the performance comparison between an isolated turbine and multi-device arrangements.

Graphs of $\alpha(\vartheta)$ for the isolated turbine and for the turbines belonging to the two layouts are shown in Fig. 6-c and 6-d. In case of the side-by-side layout, it can be noted that the behaviors of $\alpha(\vartheta)$ curves are very similar to those found for $C_{P}(\vartheta)$ (Fig. 6-a). We can infer that the upwind performance increase with respect to the isolated turbine can be justified and quantified in terms of attack angle increase, and that the latter can be explained by the $\mathrm{x}$-alignment of the oncoming flow discussed previously. The $\mathrm{C}_{\mathrm{P}}$ enhancement observed in downwind for the side-by-side turbines (Fig. 6-a) has a different explanation. It is due to a significant $U_{x}$ gain visible in downwind for the side-by-side turbines (see distribution of the normalized $U_{x}(\vartheta)$ reported in Fig. 6-e). Since an $U_{x}$ gain is only observed downwind we can infer that it is caused by a wake contraction. An increase of $U_{x}$, 
yet in upwind, can also be deemed responsible for the performance increasing found for the down-stream turbines belonging to the triangular layout, although in this case the local flow speed up is due to the blockage generated by the upstream turbine. Indeed, the attack angle augmentation that appears uniformly distributed throughout upwind (Fig. 6-d) is a consequence of an $U_{x}$ increase.

\subsection{Effects of the flow direction and distance between turbines}

The best operating TSR was found through additional simulations. The results of the averaged $C_{P}$ vs TSR are shown in Fig. 7. To verify if in case of 3-VATTs the flow direction $(\varphi)$ affects the best TSR the simulations are also repeated for $\varphi=45^{\circ}$ in case of side-by-side and for $\varphi=15^{\circ}$ in case of triangular layout. According to these results, TSR is set at 1.7 in case of isolated turbine and at 1.75 in case of the two arrangements, despite both of the layouts show that the best TSR would be 1.8. It was preferred to slightly limit the TSR of the arrangements (and therefore the maximum power output gain) in order to keep operating conditions as similar as possible to those of the isolated turbine. This prudent choice allows to more likely satisfy constraints concerning cost, maintenance and safety, such as: cavitation risk, cost of the electrical generator, structural stresses, cost of the blades. This setting was kept for all the simulations presented in sections 3.2, 3.3 and 3.4.

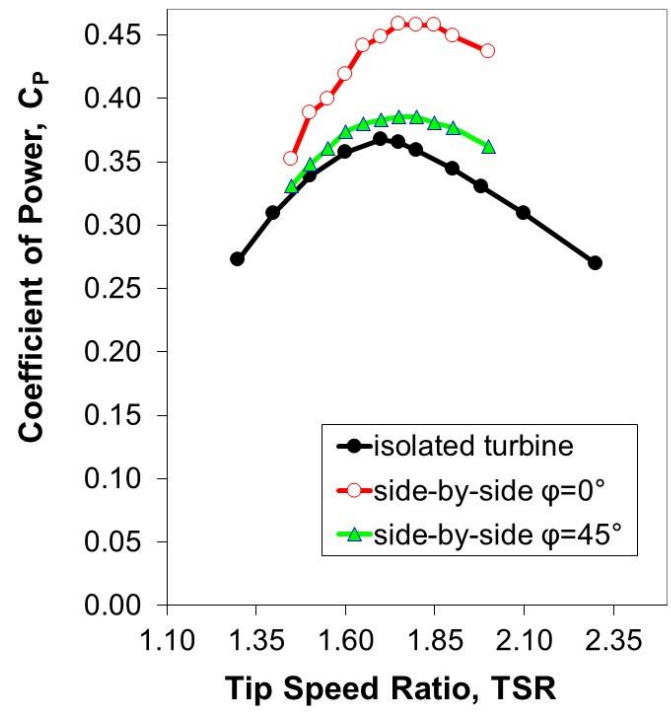

(a)

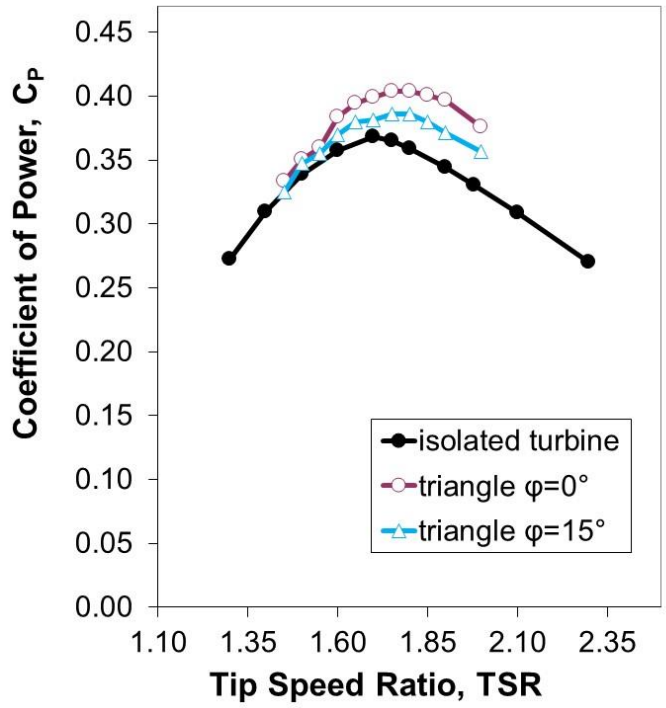

(b)

Figure 7. Averaged $C_{P}$ vs TSR predicted for side-by-side (a) and triangular (b) layouts for different flow directions, in comparison to $\mathrm{C}_{\mathrm{P}}$ of the isolated turbine.

The current direction $(\varphi)$ does not affect the power of an isolated VATT, but it does affect the power of a closely spaced VAWT arrangement. Keeping the current speed at $1.5 \mathrm{~m} / \mathrm{s}$, the averaged performance of the two layouts is predicted as a function of the flow direction and of the distance between the turbine axes. For this purpose, the simulations are performed every $15^{\circ}$ of current direction. However, due to the geometrical properties, results periodically repeat every $180^{\circ}$ for the side-by-side and every $120^{\circ}$ for the triangular layout, therefore only 12 and 8 simulations are respectively needed to completely cover the range $0^{\circ} \leq \varphi \leq 360^{\circ}$. Three distances between the axes were considered: 1.5D, 2.3D and 3.5D for side-by-side layout, and 3.0D, 4.6D and 7.0D for the triangular layout. The normalized power coefficient of the arrangement $(\mathrm{K})$ versus current direction $(\varphi)$ are reported in Fig. 7. 
These results suggest that the hydrodynamic interactions between VATTs are better exploited by the side-byside layout than the triangular since the maximum $K$ is higher (1.246 vs 1.105) and the ranges of $\varphi$ entailing $\mathrm{K}>1$ are much wider $\left(120^{\circ}\right.$ for distance between axes of $2.3 \mathrm{D}$, vs $36^{\circ}$ for distance of $\left.4.6 \mathrm{D}\right)$. On the other hand, both of the layouts experience significant efficiency losses when the wake of the upstream turbine covers one or both of the downstream turbines (for instance, $\varphi=90^{\circ}$ and $270^{\circ}$ for side-by-side layout, $\varphi=30^{\circ}$ and $90^{\circ}$ for the triangular). Due to these losses, the closer the turbines the narrower the $\varphi$ range for which a power gain is achieved with respect to the isolated turbine. However, for both of the layouts, the sum of the $\varphi$-ranges giving $K>1$ is greater than the sum of the $\varphi$-ranges giving $K<1$, with the only exception of the shortest distance adopted for the triangular layout.

In the following sections the distance between the axes is fixed to reduce the number of simulations. In case of the side-by-side layout this distance is set at 1.5D since it allows to get the maximum benefit from blockage effects at a cost of an acceptable shortening of the range of $\varphi$ allowing $K>1$. For the triangular layout the distance is set at $4.6 \mathrm{D}$ as it gives the best $\mathrm{K}$, and also implies a much higher packing factor than that achievable with a distance of $7 \mathrm{D}$.

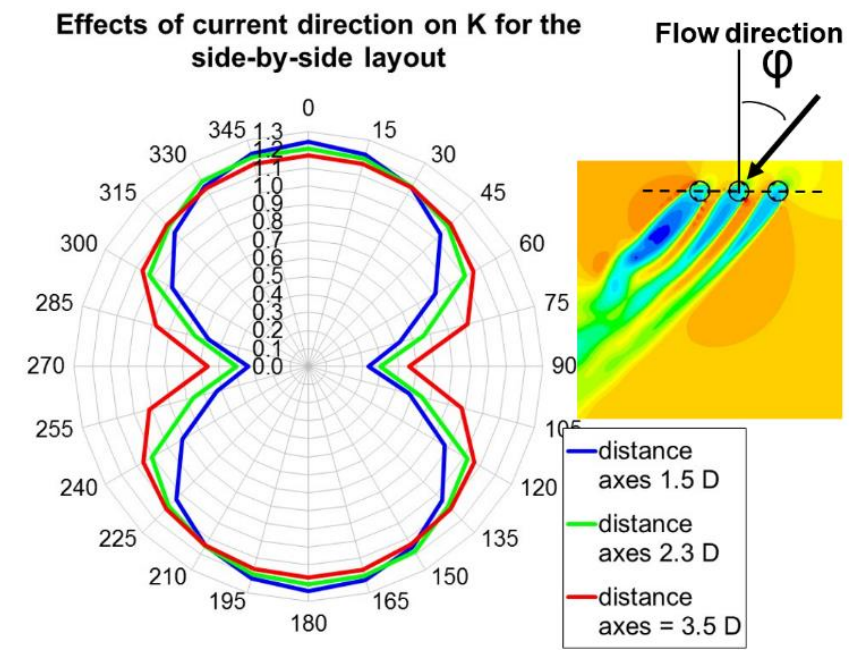

(a)

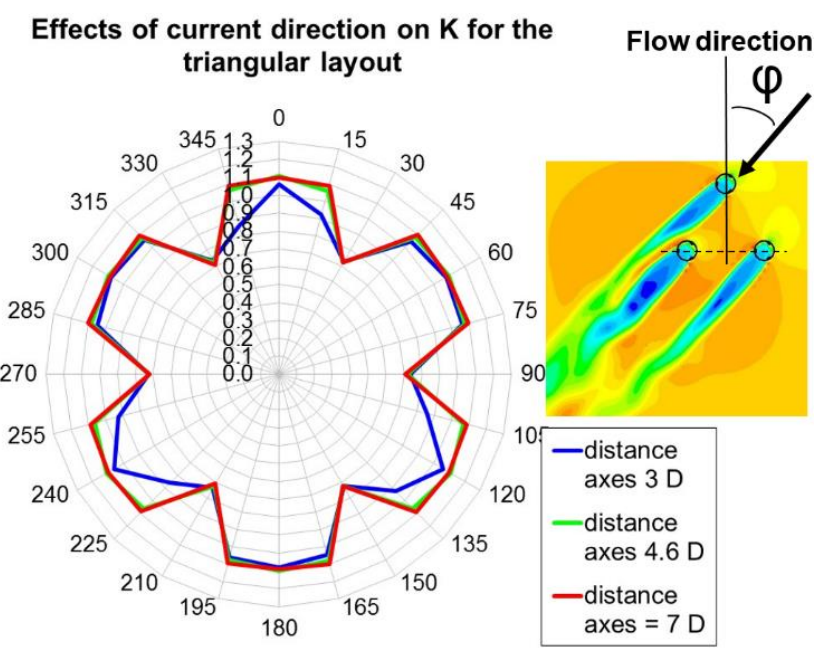

(b)

Figure 8. Normalized overall power coefficient $(K)$ versus current direction $(\varphi)$ for the side-by-side (a) and for the triangular (b) layout, predicted for different distance between axes. $\Phi$ is defined in the lateral panes (in the examples $\varphi=45^{\circ}$ ).

\subsection{Load control strategy: effects of the rated speed}

The parameter $\mathrm{K}(\varphi)$ shown in section 3.2 is obtained when the turbines work close to the optimal TSR, thus in a condition that should prevent deep flow separation ideally. It is expected that by adopting a load control strategy based on variable pitch that, by mains a proper attack angle reduction, guarantees the rated power occurrence, these fairly good $\mathrm{K}(\varphi)$ would be maintained whatever the speed of the current. In other words, for speeds greater than the rated speed, set the same pitch angle adopted for the isolated turbine, the VATTs belonging to the arrangements should give $\mathrm{K}$ values similar to that predicted in case of optimum TSR, since there are no reasons why the effects of blockage should be less effective. If a turbine is stall regulated the TSR will drop below the optimal value and the blockage effects may change substantially, therefore it is important to assess how the parameter $K(\varphi)$ varies with the speed of the current. For this purpose, a set of simulations have been executed under the assumption of using stall regulated turbines: for stream speeds lower than the rated speed the TSR is kept to 1.70 for the isolated turbine and 1.75 for the arrangements, while for higher 
stream speeds the turbine angular speed is kept constant and therefore TSR decreases leading to stall. Four rated speeds have been considered: $1.5 \mathrm{~m} / \mathrm{s}, 1.75 \mathrm{~m} / \mathrm{s}, 2.0 \mathrm{~m} / \mathrm{s}$ and $2.25 \mathrm{~m} / \mathrm{s}$. The cut-in speed is set at $0.5 \mathrm{~m} / \mathrm{s}$, and cut-off speed at $3.75 \mathrm{~m} / \mathrm{s}$. In all the simulations the orientation of the array $\varphi$ is kept at $0^{\circ}$. To take into account the tip losses, the drag of the struts, the mechanical and electrical generator losses, an overall loss coefficient of $30 \%$ has been adopted. The power generated by each turbine per meter of blade length $(\mathrm{H}=1)$, already reduced by $30 \%$, and the averaged $\mathrm{C}_{\mathrm{P}}$ are shown in Fig. 9 vs current speed.

As expected from this kind of power control, despite the power coefficient begins to decrease for current speeds slightly higher of the rated one, power continues to rise until speeds much higher than the rated one. It can be observed that the simulations reasonably reproduce the effect of the Reynolds number on $\mathrm{C}_{\mathrm{P}}$. Indeed, as long as the turbines operate at the optimal TSR the $C_{P}$ is slightly increasing with the current speed; at rated conditions $\mathrm{C}_{\mathrm{P}}$ drops faster as the rated speed decreases, since more flow separation occurs at low Reynolds. By comparing the behavior of the arrangements with that of the isolated turbine we can observe that once the rated speed is exceeded the performance drops more rapidly and consequently, above rated the power gain is much less than that found for the optimal TSR. This happens since the passive stall occurrence is accelerated by greater blade attack angles induced upwind by the flow x-alignment (Fig. 6-c) in case of the side-by-side layout, and by the current speed-up (Fig. 6-d) in case of the triangular layout. We can conclude that passive stall is a load control strategy that doesn't allow to take the most advantage from the blockage effects occurring in closely spaced VATT arrangements, unless very high rated speeds are chosen.

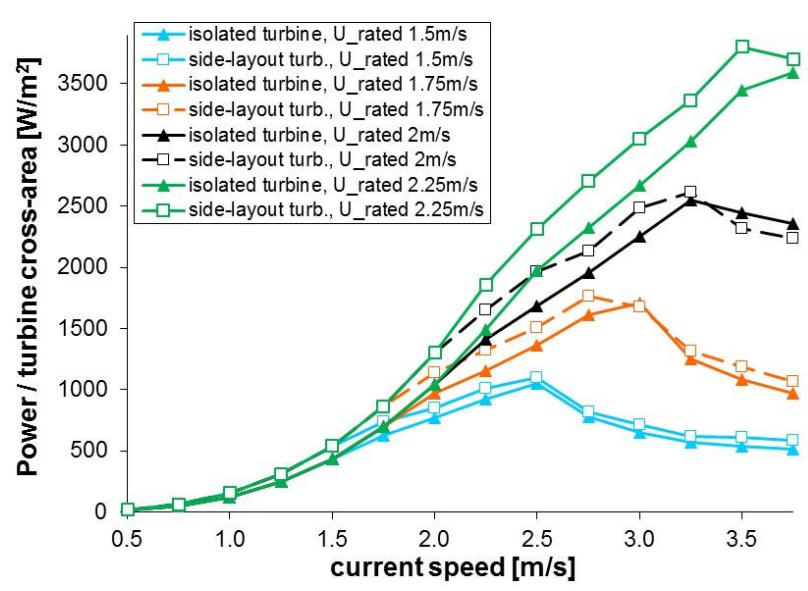

(a)

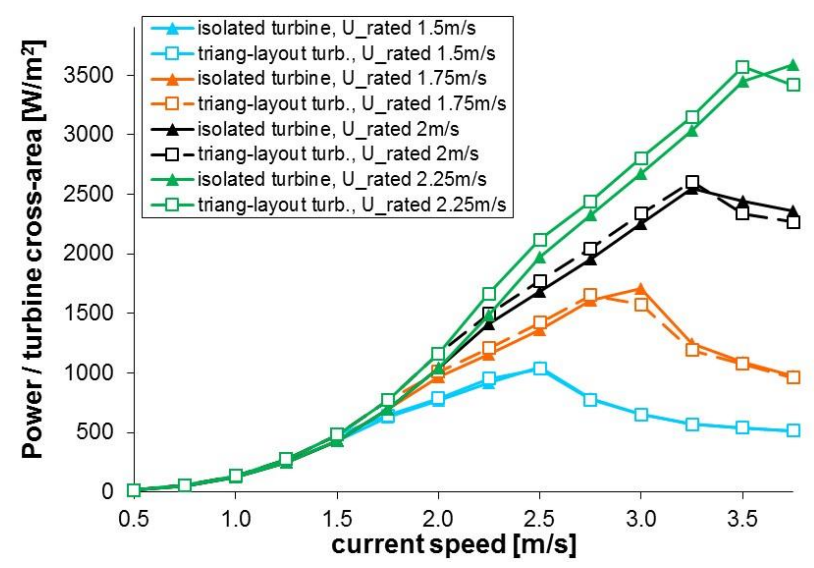

(c)

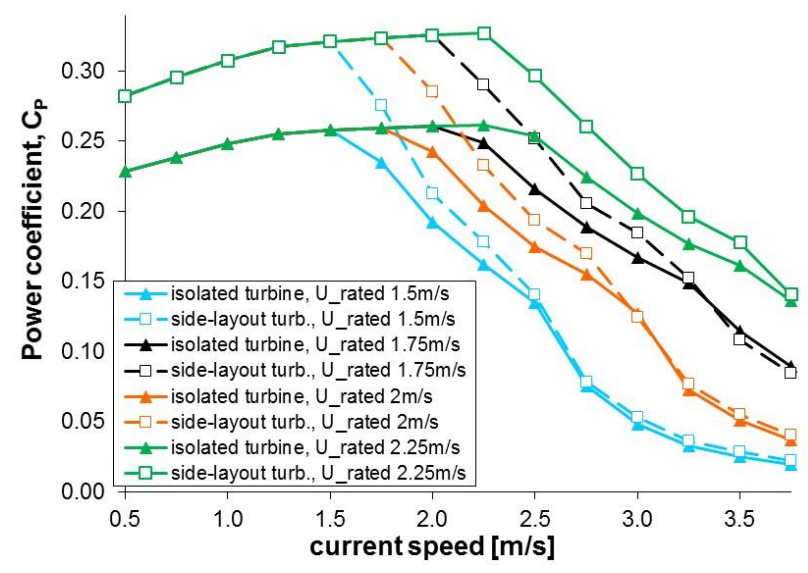

(b)

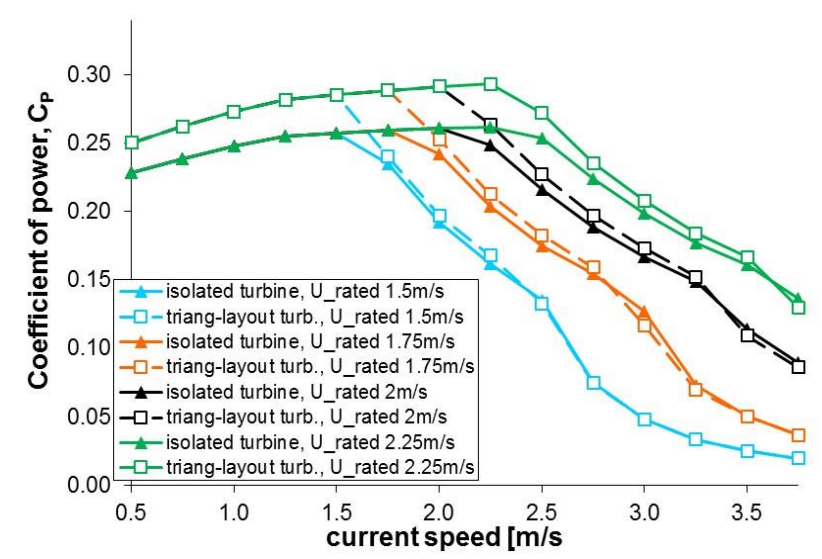

(d)

Figure 9. Power (per $\mathrm{m}^{2}$ of turbine cross-sectional area) vs current speed predicted for the isolated turbine and for the turbine belonging to side-by-side (a) and triangular (c) layouts; $\mathrm{C}_{\mathrm{P}}$ vs current speed predicted for the isolated turbine and for the turbine belonging to side-by-side (b) and triangular (d) layouts. 


\subsection{Energy yield prediction for three real cases in the English Channel}

The period of tidal currents is governed by the relative motion of sun, moon and earth, and it is about 12 hours $25 \mathrm{~min}$. The tidal current speed varies sinusoidally with time, and the flow inverts its direction about every 6 hours. However, the current direction never inverts by exactly $180^{\circ}$, especially near the coasts of islands and headlands, therefore planning is needed in choosing the optimal orientation in which to arrange an array of VATT. To harvest power from tidal currents the flow speed needs to be higher than $1.0 \mathrm{~m} / \mathrm{s}$. Channels or constrictions between islands provide some of the best sites, as the flow is fast and rectilinear.

The energy output in a period of six months is predicted for three sites in the English Channel for which high tidal stream velocities occur. Two of them - Alderney Race and St. Catherine point - are distinguished by nearly rectilinear currents while the third - Portland Bill - is characterized by non-rectilinear currents and by high dispersion of directions. Because of these particular characteristics these sites were adopted by Blunden et al. [37] in a comparative study of the energy yields from fixed and yawing HATT. Fig. 10 shows the "diamond diagrams", i.e. neap and spring speeds vs current directions, obtained from the British Admiralty Charts: AC 2669 (point-C) for Alderney Race; AC 2045 (point-F) for St. Catherine's point; AC 2615 (pointF) for Portland Bill. In the latter, it can be noted a significant swing upon flow reversal as typically occurs around headlands [38].

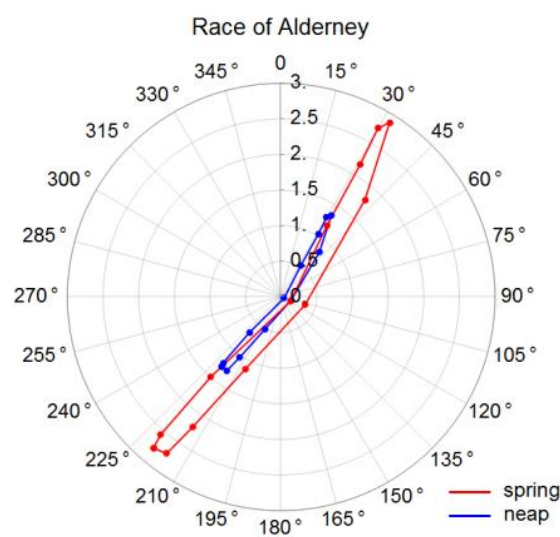

(a)

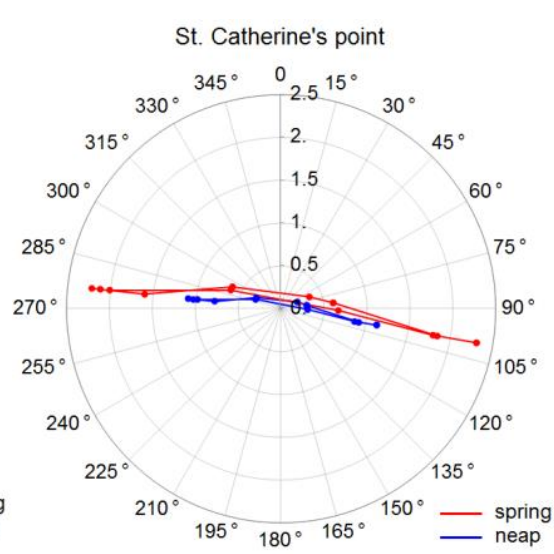

(b)

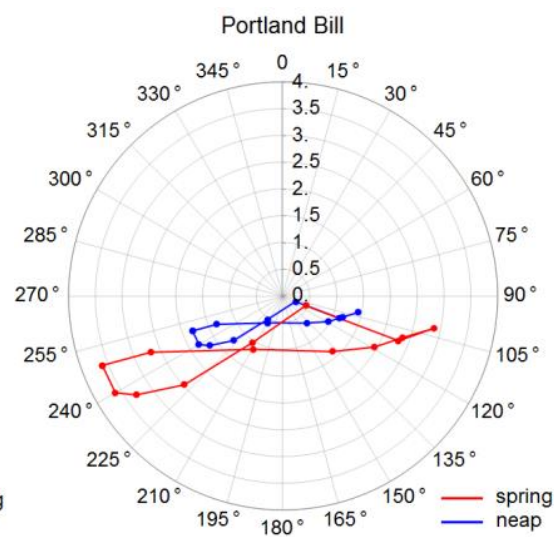

(c)

Figure 10. Neap and spring speeds vs current directions (in degrees respect to North) for Alderney Race (a), St. Catherine's point (b) and Portland Bill (c), as achieved from the Admiralty Charts number 2669 (point C), 2045 (point F), 2615 (point F), respectively.

Current absolute speed and direction at each hour are extrapolated by means of the classical graphical methodology [39] based on the availability of diamond graphs and tide heights measured once per hour, typically in a port as much as possible close to the site of interest. For this purpose, the data on the tide height which refers to the period January $1^{\text {st }} \div$ June 301993 , reported in Ref [40], have been used. The resulting absolute speeds vs time are represented in Fig. 11. 


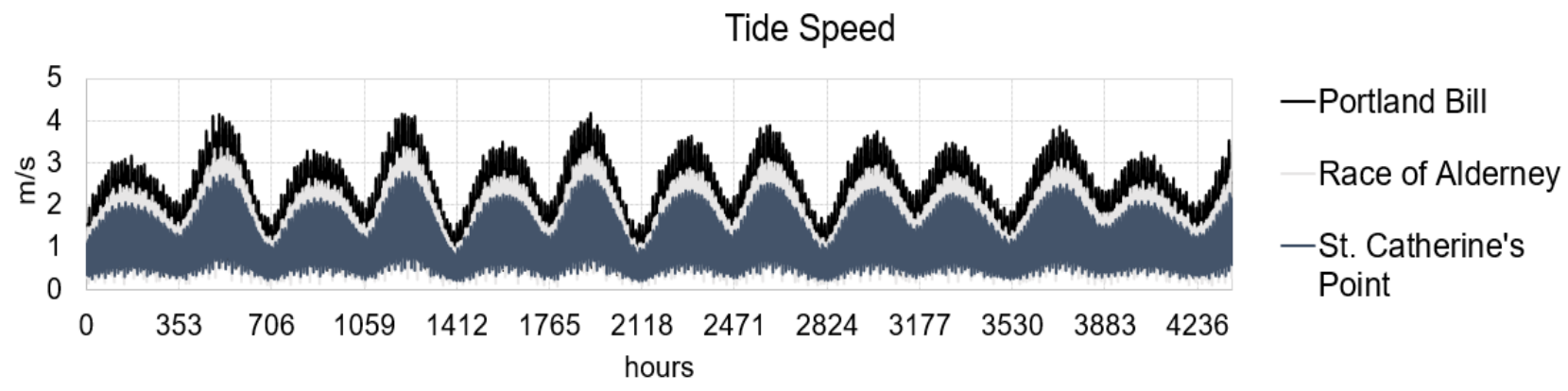

Figure 11. Absolute values of current speed vs time (from January $1^{\text {st }}$ to June 30) for Alderney Race, St. Catherine's point and Portland Bill, as extrapolated by experimental data reported in Ref. [36].

A routine has been implemented in the software Mathematica to predict the energy yield. The following inputs are needed: current speed and direction vs time; power vs time for the isolated turbine, for different rated speeds; $\mathrm{K}$ as a function of $\mathrm{U}_{\infty}$, rated speed and $\varphi$. Therefore, to complete the data of Fig. 9, further simulations have been performed for the two layouts at different $\varphi$ and rated speeds, obtaining four matrix for $\mathrm{K}$ (one for each rated speed) as a function of $U_{\infty}$ and $\varphi$. To find the best setting for each layout, i.e. the arrangement geographical orientation $(\gamma)$ that maximizes the energy output, calculations were repeated every $2.5^{\circ}$ of $\gamma$.

The energy output vs the geographical orientation of the arrangement is shown in Fig. 12. Rated speed is $1.75 \mathrm{~m} / \mathrm{s}$; three distances between axes are considered. These first simulations are performed with a fixed K, which refers to a current speed of $1.75 \mathrm{~m} / \mathrm{s}$, with the aim of focusing uniquely on the effect of the directionality characteristics of the tidal streams. For nearly rectilinear currents the graphs are similar to that of Fig. 8 , and the orientations giving the best performance coincide with the main direction of the current. For Portland Bill the maximum gain with respect to the isolated turbine is significantly smaller and graphs appear "smoothed" since many directions occur, some of these leading the wakes of upstream turbines to curtain those placed downstream. Tab. 1 shows the energy predicted as available in six months for each of the three sites, together the energy yield of the isolated turbine.

\section{Table 1}

Energy yield in 6 months (normalized by the turbine cross-sectional area) predicted for the isolated turbine assuming passive stall as load control strategy $\left[\mathrm{MWh} / \mathrm{m}^{2}\right]$. Outputs have been decreased by $30 \%$ to take into account other losses (3D fluid dynamic, mechanical, electrical generator). Last column: available energy in 6 months.

\begin{tabular}{cccccc}
\hline & $\begin{array}{c}\text { Energy yield } \\
\text { U_rated 1.5m/s }\end{array}$ & $\begin{array}{c}\text { Energy yield } \\
\text { U_rated 1.75m/s }\end{array}$ & $\begin{array}{c}\text { Energy yield } \\
\text { U_rated 2.0m/s }\end{array}$ & $\begin{array}{c}\text { Energy yield } \\
\text { U_rated 2.25m/s }\end{array}$ & $\begin{array}{c}\text { Available Energy } \\
{\left[\mathrm{MWh} / \mathrm{m}^{2}\right]}\end{array}$ \\
\hline Alderney Race & 2.127 & 2.938 & 3.621 & 4.054 & 19.202 \\
St. Catherine point & 1.796 & 2.305 & 2.641 & 2.850 & 11.589 \\
Portland Bill & 1.419 & 1.624 & 1.741 & 1.785 & 6.904 \\
\hline
\end{tabular}

The best gain in the energy yield with respect to the yield of the isolated turbine are represented in Fig. 13. Three scenarios are illustrated: (1) fixed K (as calculated at the corresponding rated speed) and perfectly rectilinear current (red dashed line); (2) fixed $\mathrm{K}$, real current directions; (3) variable $\mathrm{K}$ and real current directions. By comparing (1) and (2) one can recognize the gain lost due to the current characteristics. It can be seen that in case of Portland Bill a loss of $\sim 40 \%$ compared to the maximum gain occurs for the side-byside layout, and $\sim 30 \%$ for the triangular layout.

By comparing (2) and (3) the gain loss due to the load control strategy is revealed. Results confirm the findings of section 3.3: passive stall does not allow to completely exploit the blockage effects since the high attack angles produced by the flow $\mathrm{x}$-alignment trigger and increase the flow separation and thus the losses. The gain 
loss relatively to the maximum gain (achievable for optimal TSR, or in case of variable pitch load control) ranges from $8 \%$ to more than $50 \%$, depending on the rated speed.

To conclude, the side-by-side layout gives the best performance advantage in general, about two and half times the gain achieved by triangular layout. The most significant gain can be obtained in case of rectilinear currents (more than 20\%). However even in case of non-rectilinear currents the gain is still relevant as it exceeds $10 \%$, provided that an efficient load control strategy or a high current rated speed are adopted.

Finally, it should be observed that, despite the lower benefit, a triangular layout would allow a much greater stability of the arrangement in case a floating platform should be used.

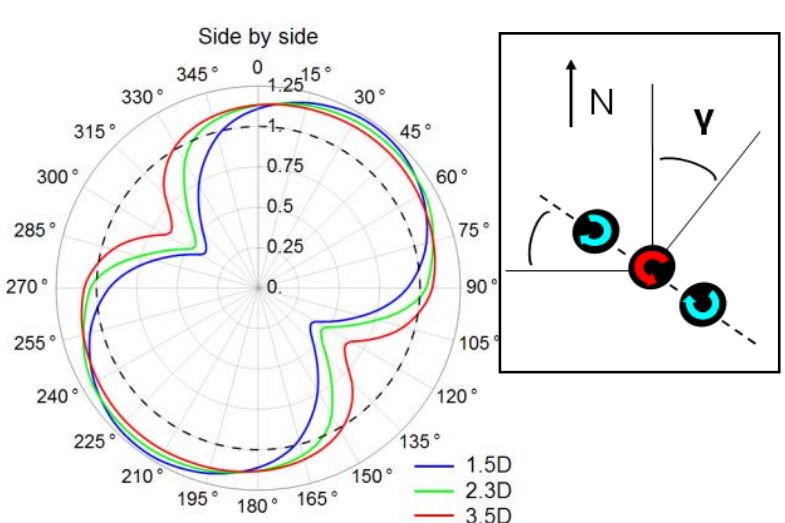

(a)

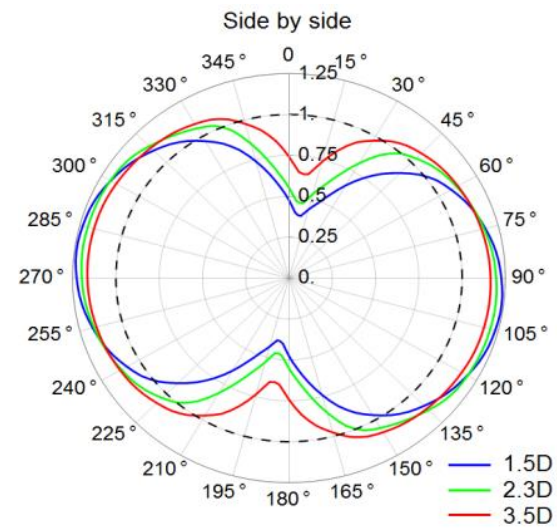

(c)

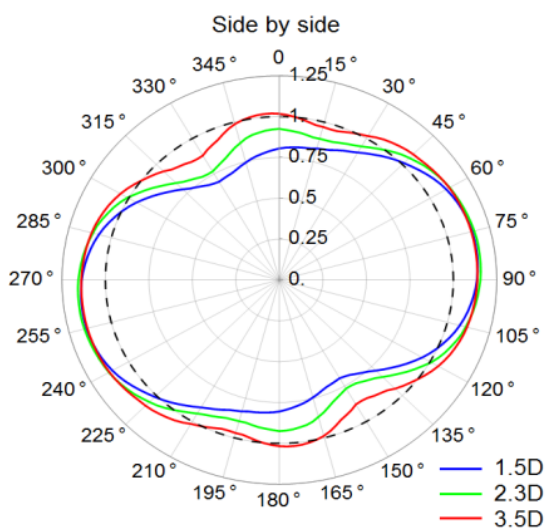

(e)

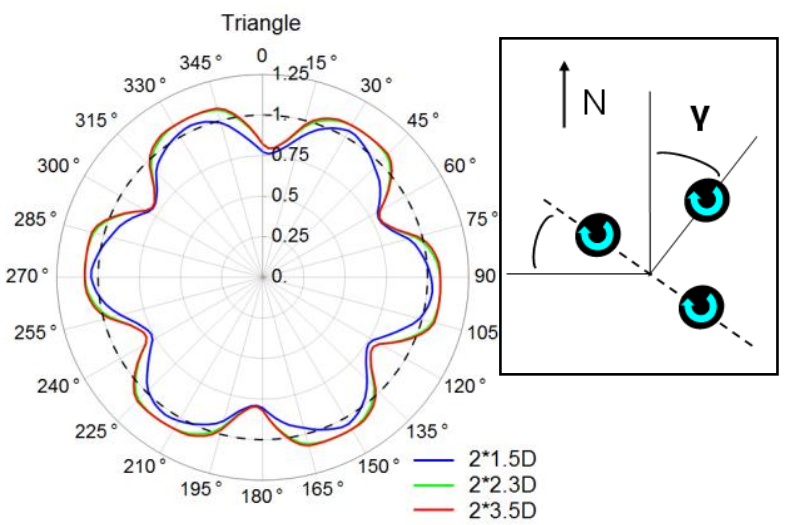

(b)

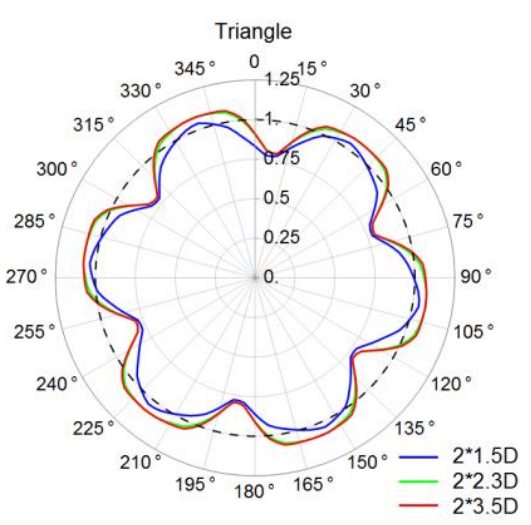

(d)

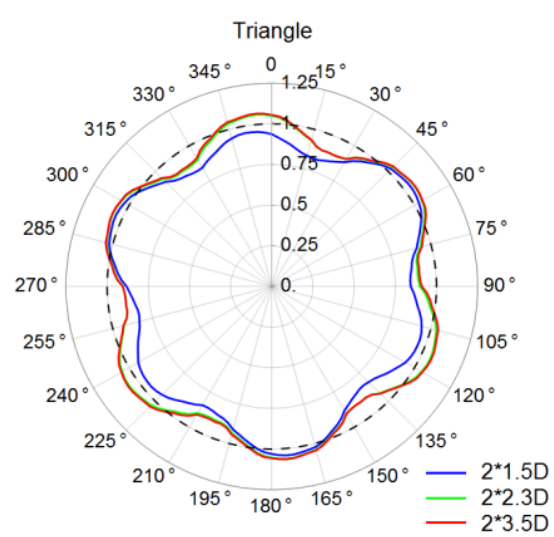

(f)

Figure 12. Energy output (normalized respect to the output of the isolated turbine) predicted for the two layouts in Alderney Race (a, b), St. Catherine's point (c, d) and Portland Bill (e, f) versus the angular orientation $\gamma$ of the arrangement. Three different distances between axes are considered. Rated speed is $1.75 \mathrm{~m} / \mathrm{s}$. Fixed values for $\mathrm{K}$ are used (the ones predicted at $1.75 \mathrm{~m} / \mathrm{s}$ ). 


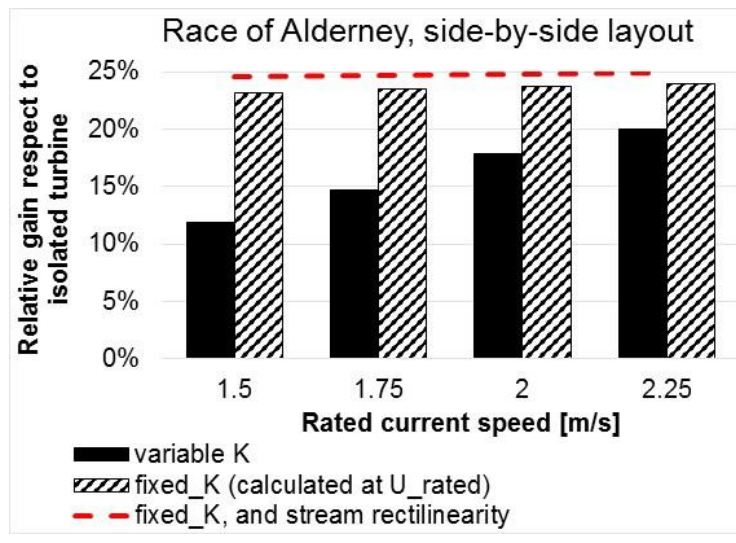

(a)

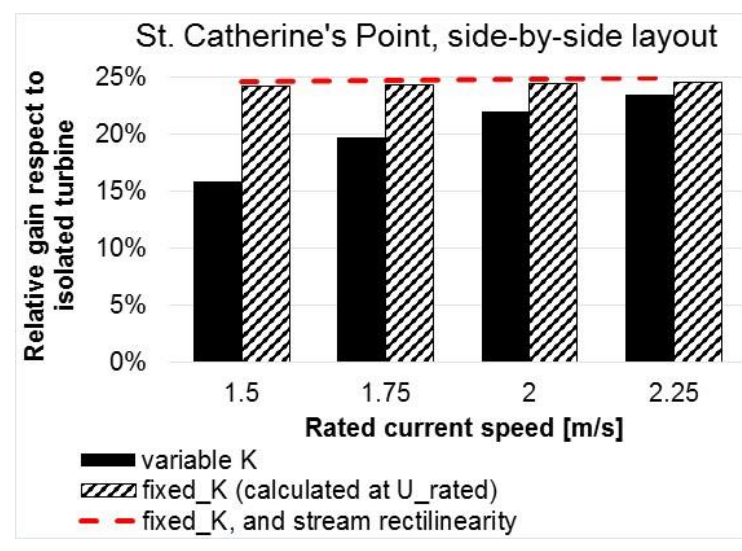

(c)

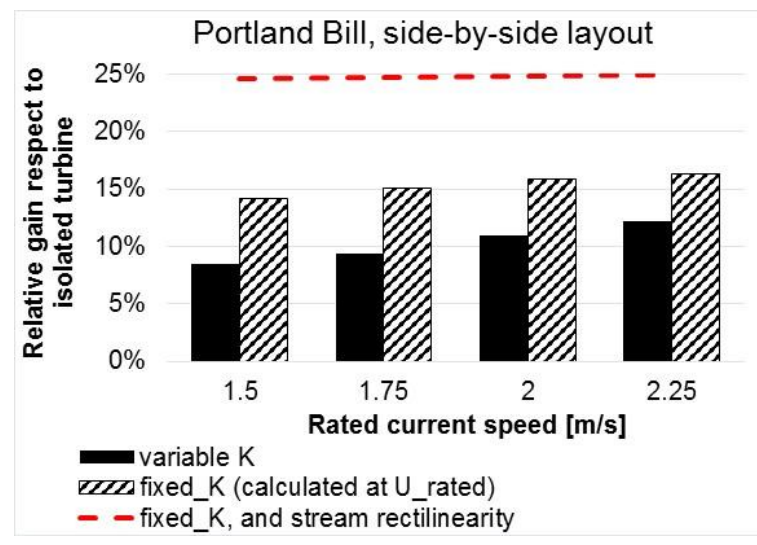

(e)

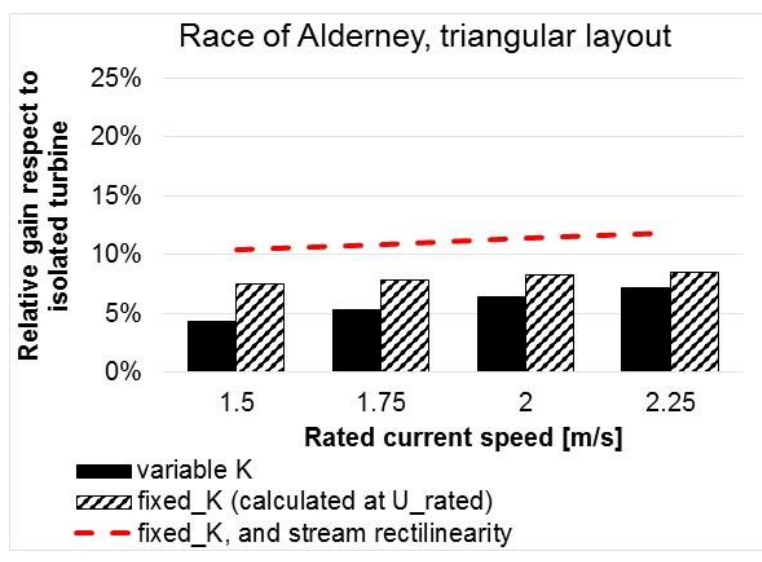

(b)

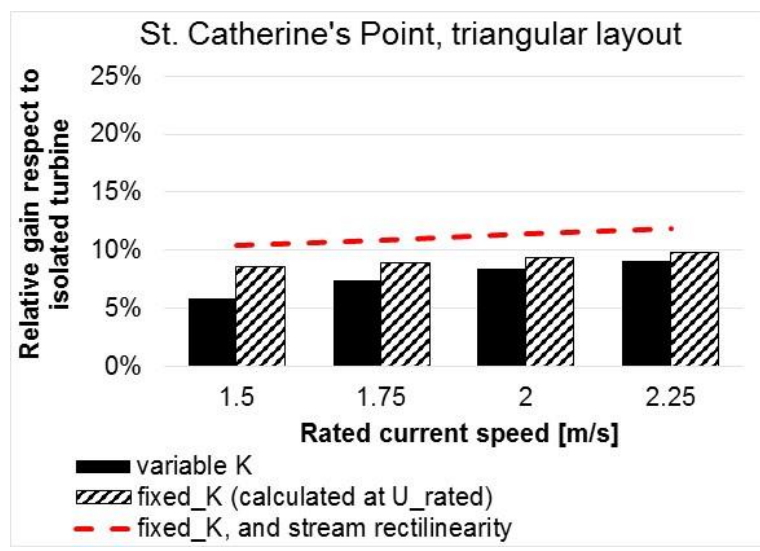

(d)

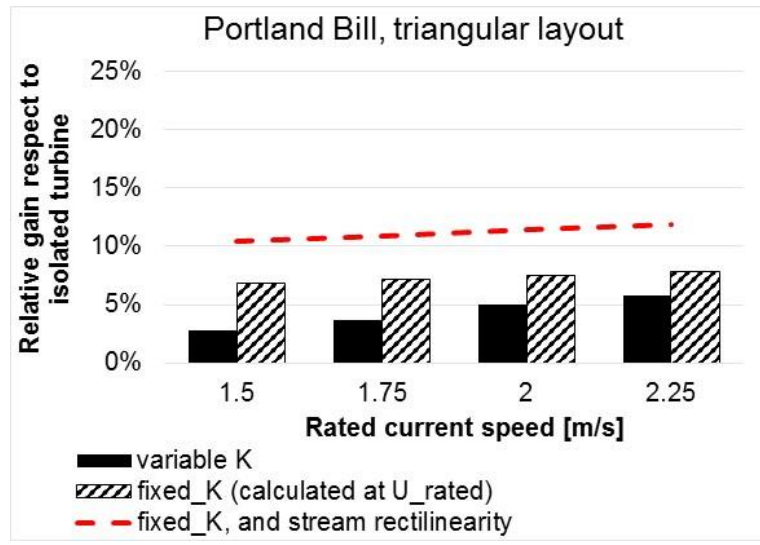

(f)

Figure 13. Relative gain in energy output averagely achieved for a turbine belonging to side-by-side and triangular layouts respect to the isolated turbine, predicted in Alderney Race (a, b), St. Catherine's point (c, d) and Portland Bill (e, f).

\section{Conclusions}

The current CFD analysis of three VATTs set in close proximity confirms what found in a previous paper focused on pairs of counter-rotating wind turbines [16], and show that three main mechanisms, all of them related to blockage, are responsible for a performance enhancing with respect to isolated turbines. These are: (1) turbine lateral blockage, that entails flow acceleration outside of the turbines and inside the aisles between adjacent turbines; (2) flow $\mathrm{x}$-alignment, that implies higher angles of attack in the upwind side; (3) wake contraction, that increases the downwind torque generation. This analysis also shows that an effective way to 
qualitatively recognize and quantitatively asses the role played by each of these effects is to graphically represent the azimuthal distribution of blade attack angle and flow x-velocity at the blade position.

Flow alignment and wake contraction only occur in a side-by-side layout, and justify the superiority of this arrangement in terms of maximum performance. A further advantage of side-by-side layouts is the wide range of current directions allowing a power gain respect to isolated turbines. This quality is expected to make sideby-side layouts advantageously adoptable even in case of non-rectilinear tidal currents.

The energy output in a period of six months has been predicted for three sites in the English Channel, two of them characterized by nearly rectilinear currents and one characterized by non-rectilinear currents and high dispersion of directions. In general, the side-by-side layout gives the best performance gain with respect to the isolated turbine, about two and half times the gain achieved by triangular layout. The gain can be obtained in case of rectilinear currents is more than $20 \%$, however even in case of non-rectilinear currents the gain is significant, surpassing $10 \%$ provided an efficient load control strategy or a high current rated speed are adopted. The effects of the load control strategy were analyzed. CFD simulations performed for different rated speeds indicates that a strategy based on passive stall does not allow to take the best advantage of the blockage effects since the high attack angles produced by the flow $\mathrm{x}$-alignment trigger massive flow separation. The loss with respect to the maximum gain, achievable if the optimal TSR was maintained ranges from $8 \%$ until more than $50 \%$, depending on the rated speed.

\section{Funding}

This research did not receive any specific grant from funding agencies in the public, commercial, or not-forprofit sectors.

\section{Acknowledgements}

The author would like to thank Edoardo Cicirello, since he implemented the routine for the energy yield calculations, performed the predictions of Fig. 12 and 13, and given help for the language revision.

\section{References}

[1] A. Orlandi, M. Collu, S. Zanforlin, A. Shires, 3D URANS analysis of a vertical axis wind turbine in skewed flows, J. Wind Eng. Ind. Aerodyn. 147 (2015) 77-84. doi:10.1016/j.jweia.2015.09.010.

[2] D.P. Coiro, F. Nicolosi, A. De Marco, S. Melone, F. Montella, Dynamic behavior of novel vertical axis Tidal current turbine: Numerical and experimental investigations. Proc. of $15^{\text {th }}$ Internet Offshore and Polar Engin. Conference, 2005, Seoul, Korea

[3] P. Chougule, S. Nielsen, Overview and Design of self-acting pitch control mechanism for vertical axis wind turbine using multi body simulation approach, Journal of Physics: Conference Series 524 (2014) 012055.

[4] L.X. Zhang, Y. Pei, Y. B. Liang, F.Y. Zhang, Y. Wang, J. J. Meng, H. R. Wang, Design and Implementation of Straight-bladed Vertical Axis Wind Turbine with Collective Pitch Control, In Proceedings of the 2015 IEEE International Conference on Mechatronics and Automation, Beijing, China, 2-5 August 2015.

[5] G. Bai, J. Jun Li, P. Fan, G. Li, Numerical investigations of the effects of different arrays on power extractions of horizontal axis tidal current turbines. Renewable Energy 53 (2013) 180-186.

[6] M. G. Gebreslassie, G. R. Tabor, M R. Belmont, Investigation of the performance of a staggered configuration of tidal turbines using CFD. Renewable Energy, Volume 80, August 2015, Pages 690-698.

[7] Draper S., N. Takafumi, Centred and staggered arrangements of tidal turbines. J. Fluid Mech. 2014, 739, 72-93.

[8] R. Malki, I. Masters, A. J. Williams, T. N. Croft, Planning tidal stream turbine array layouts using a coupled blade element momentum e computational fluid dynamics model, Renewable Energy 63 (2014) 46-54.

[9] T. Roc, D. Greaves, K. Thyng, D. Conley, Tidal turbine representation in an ocean circulation model: Towards realistic applications, Ocean Engineering 78 (2014) 95-111. 
[10] R. W. Whittlesey, S. Liska S, Dabiri, Fish schooling as a basis for vertical axis wind turbine farm design. Bioinspiration \& biomimetics, 2010, vol. 5

[11] J. O. Dabiri, Potential order-of-magnitude enhancement of wind farm power density via counter-rotating vertical-axis wind turbine arrays. Journal of renewable and sustainable energy, 2011, vol. 3.

[12] I. D. Brownstein, M. Kinzel, J. O. Dabiri Performance enhancement of downstream vertical-axis wind turbines, J. Renewable Sustainable Energy 8, 053306 (2016); doi: 10.1063/1.4964311.

[13] D. B. Araya, A. E. Craig, M. Kinzel, J. O. Dabiri, "Low-order modeling of wind farm aerodynamics using leaky Rankine bodies", Journal of renewable and sustainable energy, 2014, vol. 6, 063118.

[14] Y. Li, S. M. Calısal, Modeling of twin-turbine system swith vertical axis tidal current turbines: Part I-Power output. Ocean Engineering 37 (2010) 627-637.

[15] Feng G et al. Optimizing the Land Use for Wind Farms Using Vertical Axis Wind Turbines. PO.ID 192, Europe's premier wind energy conference and exhibition, European Wind Energy Association (EWEA), 2014, Barcelona, Spain.

[16] S. Zanforlin, T. Nishino, Fluid dynamic mechanisms of enhanced power generation by closely spaced vertical axis wind turbines, Renew. Energy. 99 (2016) 1213-1226. doi:10.1016/j.renene.2016.08.015.

[17] S. Giorgetti, G. Pellegrini, S. Zanforlin, CFD Investigation on the Aerodynamic Interferences between Medium-solidity Darrieus Vertical Axis Wind Turbines, Energy Procedia. 81 (2015) 227-239. doi:10.1016/j.egypro.2015.12.089.

[18] S. Zanforlin, F. Burchi, N. Bitossi, Hydrodynamic Interactions Between Three Closely-spaced Vertical Axis Tidal Turbines, Energy Procedia. 101 (2016) 520-527. doi:10.1016/j.egypro.2016.11.066.

[19] T. Maître, E. Amet, C. Pellone, Modeling of the flow in a Darrieus water turbine: Wall grid refinement analysis and comparison with experiments, Renew. Energy. 51 (2013) 497-512. doi:10.1016/j.renene.2012.09.030.

[20] P. Marsh, D. Ranmuthugala, I. Penesis, G. Thomas, Three-dimensional numerical simulations of straight-bladed vertical axis tidal turbines investigating power output, torque ripple and mounting forces, Renew. Energy. 83 (2015) 67-77. doi:10.1016/j.renene.2015.04.014.

[21] C. Li, S. Zhu, Y. Xu, Y. Xiao, 2.5D large eddy simulation of vertical axis wind turbine in consideration of high angle of attack flow, Renew. Energy. 51 (2013) 317-330. doi:10.1016/j.renene.2012.09.011.

[22] M.R. Castelli, A.D. Monte, M. Quaresimin, E. Benini, Numerical evaluation of aerodynamic and inertial contributions to Darrieus wind turbine blade deformation, Renew. Energy 51 (2013) 101-112.

[23] S. Lain, C. Osorio, Simulation and evaluation of a straight-bladed Darrieus-type cross flow marine turbine, J. Sci. Ind. Res. 69 (2010) 906-912.

[24] F. R. Menter, Zonal two equation k-U turbulence models for aerodynamic flows. AIAA Paper July 1993;93-2906. 24th Fluid Dynamics Conference.

[25] F. R. Menter, Two-equation eddy-viscosity turbulence models for engineering applications. AIAA Journal 1994;32(8):15981605.

[26] D. C. Wilcox, Formulation of the k-U turbulence model revisited. AIAA Journal 2008;46(11):2823-38.

[27] P. Bachant, M. Wosnik, Modeling the near-wake of a vertical-axis cross-flow turbine with 2-D and 3-D RANS, Journal of Renewable and Sustainable Energy 8, 053311 (2016); doi: http://dx.doi.org/10.1063/1.4966161

[28] FLUENT Training Material - ANSYS Release Version 14.5, Lecture Transient Flow Modeling, Introduction to ANSYS Fluent; ANSYS Inc.: Canonsburg, PA, USA, 2012.

[29] F. Balduzzi, A. Bianchini, R. Maleci, G. Ferrara, L. Ferrari, Critical issues in the CFD simulation of Darrieus wind turbines, Renew. Energy. 85 (2016) 419-435. doi:10.1016/j.renene.2015.06.048.

[30] M. Elkhoury, T. Kiwata, E. Aoun, Experimental and numerical investigation of a three-dimensional vertical-axis wind turbine with variable-pitch, J. Wind Eng. Ind. Aerodyn. 139 (2015) 111-123. doi:10.1016/j.jweia.2015.01.004.

[31] A. Rezaeiha, I. Kalkman, B. Blocken, CFD simulation of a vertical axis wind turbine operating at a moderate tip speed ratio: Guidelines for minimum domain size and azimuthal increment, Renew. Energy. 107 (2017) 373-385. doi:10.1016/j.renene.2017.02.006.

[32] S. Kiho, M. Shiono, K. Suzuki,The power generation from tidal currents by Darrieus turbines. WREC 1996.

[33] Shiono M, Suzuki K, Kiho S. An Experimental Study of the Characteristics of a Darrieus Turbine for Tidal Power Generation. Electrical Engineering in Japan, Vol. 132, No. 3, 2000.

[34] C.J.S. Ferreira, H. Bijl, G. van Bussel, G. van Kuik, Simulating Dynamic Stall in a 2D VAWT: Modeling strategy, verification and validation with Particle Image Velocimetry data, J. Phys. Conf. Ser. 75 (2007) 12023. doi:10.1088/1742-6596/75/1/012023.

[35] M.R. Castelli, G. Pavesi, L. Battisti, E. Benini, G. Ardizzon, Modeling Strategy and Numerical Validation for a Darrieus Vertical Axis Micro-Wind Turbine, Int. Mech. Eng. Congr. Expo. (2010). doi:10.1115/IMECE2010-39548.

[36] S. Zanforlin, S. Letizia, Improving the Performance of Wind Turbines in Urban Environment by Integrating the Action of a Diffuser with the Aerodynamics of the Rooftops, Energy Procedia. 82 (2015) 774-781. doi:10.1016/j.egypro.2015.11.810.

[37] L. S. Blunden, W. M. J. Batten, A. S. Bahaj, Comparing Energy Yields From Fixed and Yawing Horizontal Axis Marine Current Turbines in the English Channel, In: Proceedings of the ASME 2008 27th International Conference on Offshore Mechanics and Arctic Engineering, American Society of Mechanical Engineers.

[38] L. S. Blundel, A. S. Bahaj, Initial evaluation of tidal stream energy resources at Portland Bill, UK. Renewable Energy 31 (2006) 121-132.

[39] L. Grindley, Tides and tidal streams (2014) https://www.slideshare.net/lancergrindley/tides-revision-lrg

[40] RYA Practice navigation tables for yachtsmen, published by Royal Yachting Association (RYA), 1998 